$25.1 \mid 2021$

\title{
Varia
}

\section{Le culte de Maxime de Riez : premiers jalons (I)}

\section{Thierry Pécout}

\section{(2) OpenEdition}

\section{Journals}

\section{Édition électronique}

URL : https://journals.openedition.org/cem/18054

DOI : $10.4000 /$ cem. 18054

ISSN : 1954-3093

Éditeur

Centre d'études médiévales Saint-Germain d'Auxerre

\section{Référence électronique}

Thierry Pécout, « Le culte de Maxime de Riez : premiers jalons (I) », Bulletin du centre d'études médiévales d'Auxerre | BUCEMA [En ligne], 25.1 | 2021, mis en ligne le 25 juin 2021, consulté le 22 septembre 2022. URL : http://journals.openedition.org/cem/18054 ; DOI : https://doi.org/10.4000/ cem. 18054

Ce document a été généré automatiquement le 22 septembre 2022.

\section{c) (†) (2)}

Creative Commons - Attribution - Pas d'Utilisation Commerciale - Partage dans les Mêmes Conditions 4.0 International - CC BY-NC-SA 4.0

https://creativecommons.org/licenses/by-nc-sa/4.0/ 


\section{Le culte de Maxime de Riez : premiers jalons (I)}

Thierry Pécout

NOTE DE L'ÉDITEUR

Le présent article est publié en deux livraisons : I dans Bucema, 25/1; II en 25/2 (2021). 
Maxime est considéré comme le fondateur du siège épiscopal de Riez. Son culte s'y déploie dès sa mort ${ }^{1}$. Pourtant, passé le $\mathrm{VII}^{\mathrm{e}}$ siècle, il y connaît une longue éclipse avant d'être restauré au XIII ${ }^{\mathrm{e}}$ siècle. Ce rythme est probablement un effet de sources. Mais il recèle sans doute aussi quelque rupture mémorielle favorisant les remotivations de la figure de ce moine évêque. Exaltant à l'origine un idéal de sainteté aristocratique et monastique, celle-ci est progressivement mise au service de l'autorité épiscopale. Dans un même laps de temps, la vénération pour Maxime semble se diffuser dans des zones fort éloignées de la Provence centrale : les pays flamands, le diocèse de Thérouanne, la basse vallée de la Seine, la vallée du Rhône, le Jura, les Corbières, le nord de la péninsule italienne. Il s'agit là sans doute d'appropriations locales d'un nom auquel des textes antiques donnent de l'éclat, à l'appui des recueils qui les diffusent, qu'il s'agisse de légendiers ou de martyrologes. De surcroît, la modestie de sa cité d'origine place son clergé dans l'incapacité de revendiquer efficacement le monopole du culte de Maxime. Lorsque des collections de légendiers se constituèrent au sein de réseaux monastiques, bénédictins puis cisterciens, Maxime prit place parmi les plus vénérables abbés, porté par une antique Vita de haute tenue rhétorique et propre à modeler l'idéal de l'évêque réformé. Il devient dès lors malaisé d'apprécier si c'est le modèle de sainteté propre à ce récit qui motive ses collecte et diffusion ou bien sa seule antiquité. L'écheveau de pareils processus d'appropriation ne saurait se démêler, tant ils s'opèrent dans le silence des sources, même si quelques hypothèses sont ici proposées. Ils mettent en jeu une histoire locale et une documentation écrite circulant à une tout autre échelle, pourvoyeuse de personnalités prestigieuses au prix de quelques réécritures adaptatives. Mis en perspective dans la longue durée, ce culte nous invite à reconsidérer les saintetés épiscopales, au-delà de leur apparent immobilisme et dans toute leur plasticité et leur force instituante.

\section{De l'ascète au patron}

2 Le personnage historique de Maxime, qui fut successivement moine puis abbé de SaintHonorat de Lérins (ca 427-428-ca 434) avant d'exercer l'épiscopat à Riez (ca 434-av. 462), est relativement bien connu ${ }^{2}$. L'historiographie l'estime créateur de ce siège, mais l'installation d'un évêque à Riez doit sans doute précéder de peu l'entrée en fonction de notre saint ${ }^{3}$. Natif de cette même cité, Maxime est issu de l'aristocratie locale : il dispose de possessions au nord du diocèse, tel le vicus proprius de Cornet ${ }^{4}$. Tout comme son successeur Fauste, Maxime procède d'une intelligentsia de haut rang férue d'ascèse et formée au monastère de Lérins. Après y avoir occupé l'abbatiat, il obtient une charge 
épiscopale en Gaule ${ }^{5}$. Le prestige social et le rayonnement intellectuel de ses évêques ne sont sans doute pas étrangers à la consécration passagère de Riez en 439, lorsqu'un concile s'y tient sous l'autorité d'Hilaire d'Arles (401-449) ${ }^{6}$. Maxime assiste également aux assemblées d'Orange en 441 et de Vaison l'année suivante ${ }^{7}$. Il est encore mentionné comme évêque en 451 dans une lettre des prélats de Gaule au pape Léon ${ }^{8}$. Sa présence au concile d'Arles est signalée vers 449-4619. En 462 puis vers 470, son successeur Fauste est attesté au siège de Riez ${ }^{10}$. La mort de Maxime peut donc se situer dans le courant des années 450 et au plus tard vers 461-462.

L'épiscopat de Maxime correspond à un temps d'emprise de la nouvelle religiosité sur le patrimoine architectural de l'antique Apollinaris des Réiens, désormais dénommée civitas Reiensium ou Regensium ${ }^{11}$. Le développement urbain et monumental est servi par la remarquable prospérité économique des $\mathrm{V}^{\mathrm{e}}$ et $\mathrm{VI}^{\mathrm{e}}$ siècles ${ }^{12}$. Un groupe cathédral est attesté à Riez dès le premier tiers du $\mathrm{v}^{\mathrm{e}}$ siècle, dans la ville antique bâtie au sein d'une plaine alluviale (fig. 1).

Fig. 1 - La cité de Riez à la fin du XIV siècle sur fond de cadastre du XIX $X^{\mathrm{e}}$ siècle.

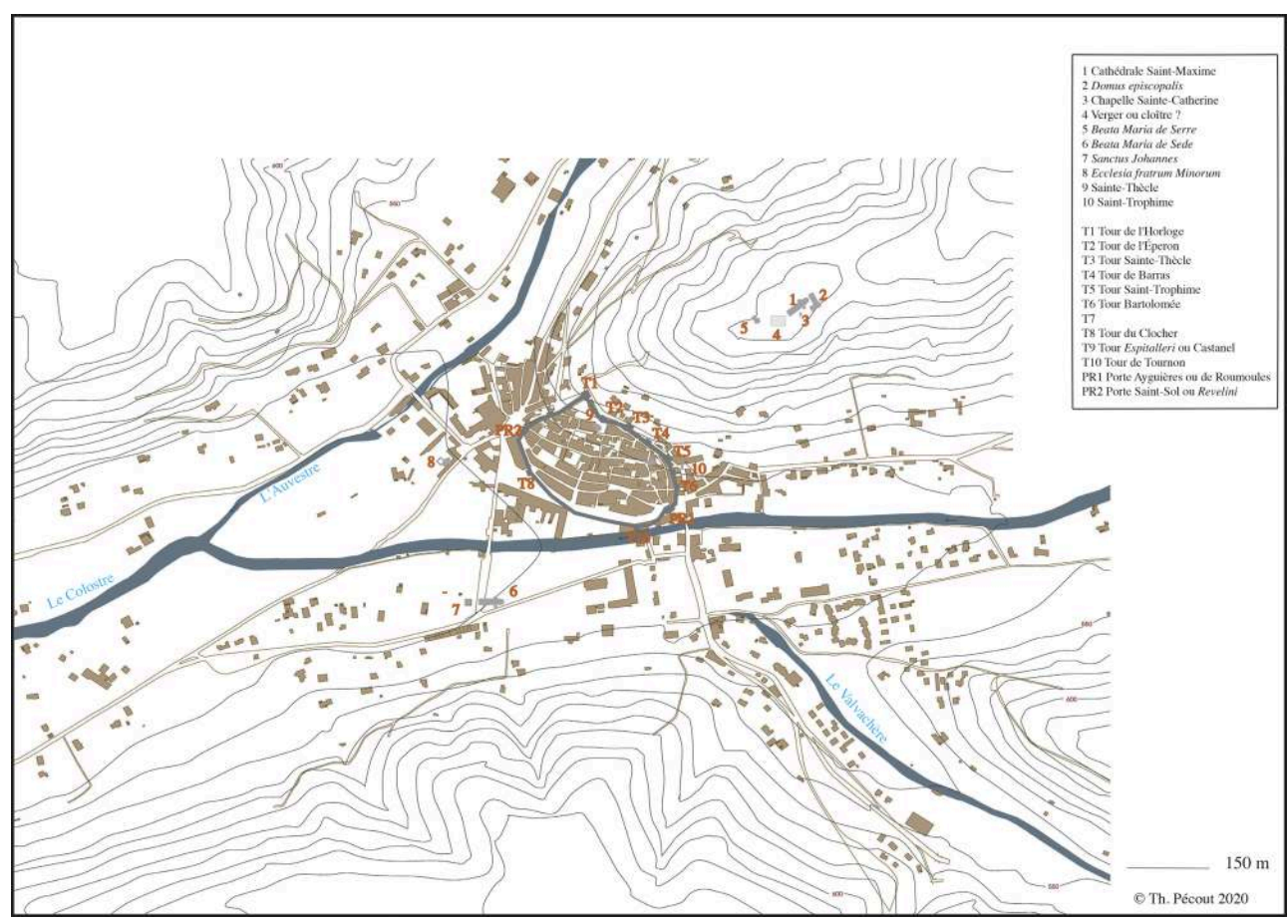

La localisation des édifices du groupe cathédral médiéval sur la colline Saint-Maxime est théorique. DAO T. Pécout, UMR LEM-CERCOR.

4 La première cathédrale, connue sous le vocable de Sainte-Marie-du-Siège au Moyen Âge et flanquée d'un baptistère, reste l'église de l'évêque pendant le haut Moyen Âge avant de se trouver supplantée par le sanctuaire construit sur la hauteur dominant le site antique $^{13}$. Maxime fait en effet édifier une église sur ce relief, dédiée à saint Alban. Dans la ville basse, il implante une basilique funéraire destinée à abriter sa dépouille, sous le titre de Pierre. Mais ses restes mortels sont vraisemblablement transférés vers l'église haute qui prend désormais le vocable de Maxime ${ }^{14}$. C'est cette église qui remplace comme cathédrale l'édifice antique situé en contrebas, à une date indéterminée comprise entre les $\mathrm{VII}^{\mathrm{e}}$ et $\mathrm{XI}^{\mathrm{e}}$ siècles. Aussi Maxime fait-il figure de bâtisseur, comme le 
souligne la documentation hagiographique élaborée dès les lendemains de sa mort (cf. Annexes, 1a-1c).

Lorsque survient celle-ci, l'évêque Fauste compose un panégyrique à la mémoire de son prédécesseur (cf. Annexes, 1a) ${ }^{15}$. Sa rédaction semble postérieure à 461-462 et antérieure à l'exil de l'auteur ordonné par le roi arien Euric, entre 478 et $484^{16}$. À moins que l'on considère que c'est justement durant sa disgrâce que Fauste a donné sa forme définitive à ce texte. Il donne quelque peu la substance de la Vita élaborée un siècle plus tard, mais son propos demeure avant tout typologique et marqué par les codes rhétoriques propres au milieu de l'auteur. Maxime apparait alors comme un guide spirituel, artisan, à la suite d'Honorat, d'une quête intérieure empreinte d'ascèse et marquée par la spiritualité du désert lérinien que Fauste s'efforce de promouvoir dans ses sermons ${ }^{17}$. C'est moins le saint évêque qui est mis en avant qu'une pratique volontariste de la vertu, spécifique à ce milieu aristocratique, source de légitimité et d'inspiration de son œuvre pastorale. Cette perspective transparait d'ailleurs chez d'autres contemporains, qu'il s'agisse de Sidoine Apollinaire s'adressant à Fauste ou bien encore d'Eucher louant la solitude lérinienne ${ }^{18}$.

\section{L'étape de la Vita}

6 Au siècle suivant, un miracle sur la tombe du saint recensé par Grégoire de Tours (cf. Annexes, 1d $)^{19}$ témoigne de la vigueur de la dévotion qui lui est localement rendue. C'est alors que ce culte se structure. La Vita Maximi composée à la fin du même siècle est une œuvre de commande de l'évêque Urbicus, l'un des lointains successeurs de Maxime, destinée à fixer des souvenirs et des usages remontant à quelques générations (cf. Annexes, 1c) ${ }^{20}$. La Vita est rédigée par un Dynamius patricius, grand personnage et diplomate doté d'une solide culture classique, gravitant dans un milieu lié à Lérins et à Arles $^{21}$. L'identification de cet auteur reste certes problématique: un Dynamius mentionné par Grégoire de Tours a exercé la fonction de rector Provincice vers 580-585 au bénéfice du roi Burgonde, un homonyme fut administrateur du patrimoine des Gaules pour le pape Grégoire $\mathrm{I}^{\mathrm{er}}$ jusqu'en $595^{22}$. Quant au commanditaire de la Vita Maximi, il n'est connu que par quelques mentions permettant de dater la rédaction de cette œuvre vers $590^{23}$. Celle-ci marque une étape nouvelle dans le développement d'une dévotion liée au miracle, manifestation essentielle de la virtus du saint. À partir du tombeau de celui-ci et sous l'instigation de l'évêque, peut-être aussi de la famille, elle s'inscrit désormais dans sa cité et s'attache au pouvoir de son pasteur. Ce confesseur, fondateur de son Église et patron, est désormais garant d'un certain patriotisme municipal ${ }^{24}$. Vie sainte, gouvernement de son Église et miracles témoignent de son aura protectrice, tandis que la dévotion qu'il suscite enracine sa ville, son paysage monumental et ses élites dans une nouvelle continuité historique.

7 Pourtant, si le culte de Maxime est précocement signalé à Riez, la nuit documentaire qui tombe sur le $\mathrm{VII}^{\mathrm{e}}$ siècle rend son étude fort malaisée. La mention la plus ancienne évoquant une église dédiée au saint évêque ne remonte qu'au début du $\mathrm{x}^{\mathrm{e}}$ siècle (cf. tab.4). On peut vraisemblablement dater de la période s'étendant du vil siècle à l'an Mil les dédicaces des différentes églises vouées à Maxime, attestées seulement aux XI et $\mathrm{XII}^{\mathrm{e}}$ siècles et situées principalement sur les confins du diocèse (fig. 2). 
Fig. 2 - Le diocèse médiéval de Riez et les églises dédiées à Maxime.

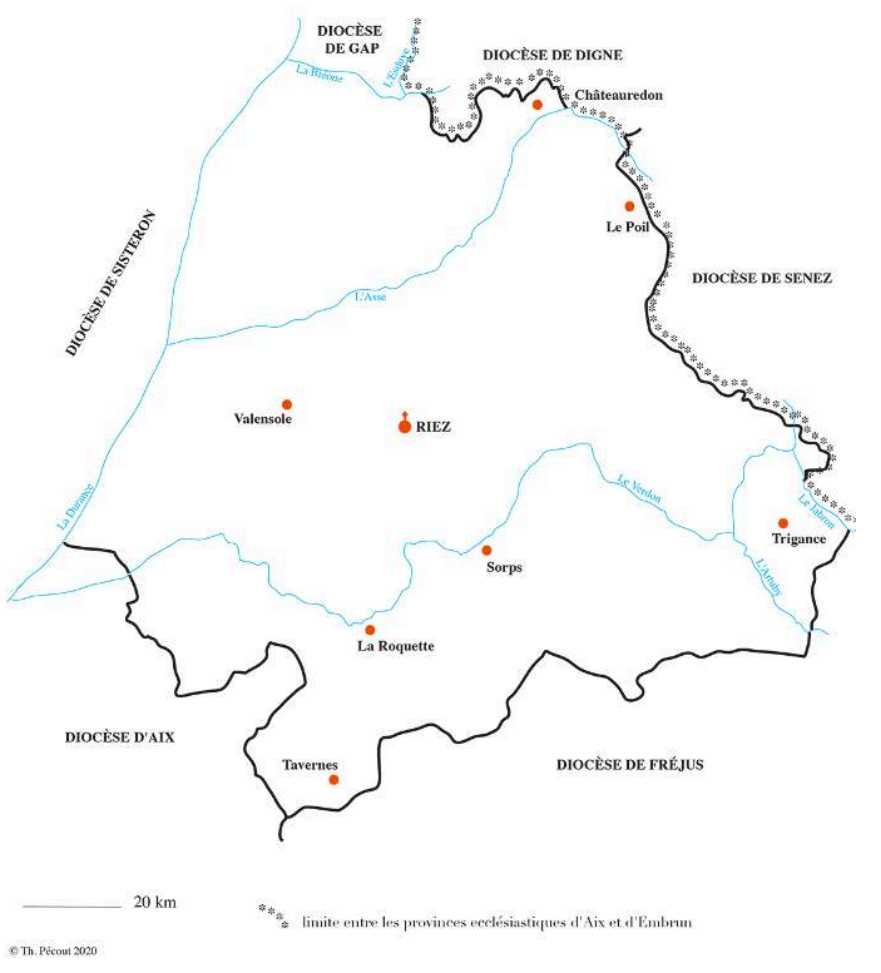

DAO T. Pécout, UMR LEM-CERCOR.

8 Ce sont là les rares traces de la persistance plausible d'un culte qui paraît toujours attaché à l'identité diocésaine ${ }^{25}$.

9 Les documents écrits postérieurs à sa Vita consistent en éloges martyrologiques attestant la circulation de celle-ci (cf. Annexes, 1h). À la fin du vi siècle, le martyrologe hiéronymien ${ }^{26}$ dans sa recension d'Auxerre comporte un certain nombre de saints provençaux, tels Honorat ou Hilaire pour le siège d'Arles, Victor pour Marseille et Eutrope pour Orange. Mais il ignore Maxime, tout comme Mitre d'Aix, du fait sans doute du caractère alors récent de leur culte ${ }^{27}$. De même, au tournant des VIII $^{\mathrm{e}}$ et $\mathrm{IX}^{\mathrm{e}}$ siècles, Maxime n'est pas non plus intégré au sanctoral des Églises romaine et franque, tel qu'il a pu être reconstitué par Victor Leroquais à partir d'un examen des sacramentaires grégorien et gélasien ${ }^{28}$. Mais le texte de Dynamius a sans doute précocement rejoint les bibliothèques des savants et des lettrés, tout particulièrement à Arles. Le $\mathrm{IX}^{\mathrm{e}}$ siècle marque une première période d'appropriation de la figure maximienne, alors que la restauration carolingienne conduit à une refondation des Églises provençales et à la promotion d'un nouveau monachisme. À l'orée du IX siècle au plus tard, la Vita Maximi sert ainsi de modèle à celle de Virgile, évêque d'Arles, l'auteur attribuant à son héros la biographie de Maxime (cf. Annexes, 1e) ${ }^{29}$. Ce jalon témoigne de la réception du texte de Dynamius en Provence au moins dans les milieux arlésiens, sans doute dans un entourage restreint puisque l'hagiographe de Virgile ose manipuler à loisir la Vita Maximi. De même dans les Églises lyonnaise et viennoise. Maxime se voit inscrit au martyrologe lyonnais rédigé avant 806 et à sa suite chez Florus, Adon puis Usuard, qui connaissaient manifestement la Vita de Dynamius ${ }^{30}$. La notice d'Usuard fige l'éloge martyrologique de Maxime, évêque et confesseur, au 27 novembre ${ }^{31}$. Enfin, le martyrologe hiéronymien s'enrichit d'une mention de Maxime 
$\mathrm{au} \mathrm{XI} \mathrm{I}^{\mathrm{e}}$ siècle, dans une leçon rédigée dans la région de Corbie $^{32}$, non loin d'une zone où nous verrons s'implanter le culte du saint.

À la fin du IX $x^{e}$ siècle, par le biais des martyrologes, Maxime se range parmi les saints susceptibles d'être connus dans l'ensemble de la chrétienté. C'est du IX siècle également que datent les manuscrits les plus anciens de sa Vita, rédigés presque sans exception dans des zones extérieures à la Provence: tel peut-être le manuscrit de Chartres, ou plus sûrement celui de Saint-Maur-des-Fossés, ou encore le légendier en deux éléments de la Bibliothèque Vaticane issu du fonds légué par la reine Christine de Suède, mais provenant de Fleury-sur-Loire (cf. tab. 3). La figure maximienne constitue désormais un vénérable modèle de saint moine et évêque, aux côtés de ses homologues lériniens et arlésiens, et circule au sein d'amples réseaux monastiques. La refondation carolingienne a probablement joué un rôle déterminant dans la fixation de ce corpus de personnalités épiscopales et abbatiales.

Reçu : 5 décembre 2020 - Accepté : 13 avril 2021

\section{ANNEXES}

Les textes sont classés par ordre chronologique de composition et non par typologie documentaire.

\section{Abréviations}

AD13 : Marseille, Archives départementales des Bouches-du-Rhône.

Bartel : S. BARTEL, Historica et chronologica prcesulum sanctoe Regiensis ecclesice nomenclatura, Aix, 1636.

CAC : Recueil des chartes de l'abbaye de Cluny, éd. A. BERNARD et A. BRUEL, Paris, 1880-1894.

CSV : Cartulaire de l'abbaye de Saint-Victor de Marseille, éd. B. GUÉRARD, Paris, 1857.

GCNN : J.-H. ALBANÈs, L. FILLET et U. CHEVALIER, Gallia christiana novissima, t. 1, Montbéliard, 1899.

Gennaro : Dinamii vita sancti Maximi episcopi Reiensis. Fausti Reiensis sermo de sancto Maximo episcopo et abbate, éd. S. GENNARO, Catane, 1966.

Wiederhold : W. WIEDERHOLD, Papsturkunden in Frankreich. Reiseberichte zur Gallia Pontificia, t. 1 (1906-1910), vol. 4 (Provence mit Venaissin, Uzegois, Alais, Nemosez und Nizza), Rome, 1985. 


\section{Le dossier hagiographique de Maxime de Riez}

\section{a. BHL 5852}

Sermon XXXV, panégyrique prononcé après la mort de Maxime (ca 461-462). S'il a pu inspirer la Vita Maximi, son propos typologique en diffère nettement. Il fut peut-être composé entre les années 461 et 478 . Le texte est généralement attribué à Fauste de Riez († ca 495) $)^{33}$. L'édition de François Glorié établie d'après Jean Leroy émet toutefois quelques réserves sur l'attribution de la collection à Fauste, en suggérant que le sermon aurait été introduit au sein des œuvres dites d'Eusebius Gallicanus par le milieu entourant Césaire d'Arles (502-542), voire par ce dernier.

Éd. : L. sURIUS, De probatis sanctorum historiis, t. 6, Cologne, 1575, p. 597-601. V. BARRALIS, Chronologia sanctorum et aliorum virorum illustrium ac abbatum sacrce insuloe Lerinensis, t. 2, Lyon, 1613, p. 115-119. Gennaro, p. 128-153. EUSEBIUS GALLICANUS, Collectio Homiliarum. Sermones extravagantes, éd. F. GLORIÉ, Turnhout, 1970, XXXV (34), p. 401-415. P.-A. JACOB et P. Boulhol (éd.), Maxime de Riez, entre l'histoire et la légende, Valensole, 2014, p. 158-193.

Tab. 1 - Les manuscrits de BHL 5852.

\begin{tabular}{|c|c|c|c|}
\hline Localisation des manuscrits & Datation & Provenance & Caractéristiques \\
\hline $\begin{array}{l}\text { BRUXELLES, Bibliothèque royale de } \\
\text { Belgique, ms.1651-1652 (1316), } \\
\text { fol. } 33 \mathrm{v}^{\circ}-37 \mathrm{v}^{\circ}\end{array}$ & ca $800-825^{(a)}$ & $\begin{array}{l}\text { abbaye } \\
\text { Longpont? }\end{array}$ & $\begin{array}{l}\text { Recueil de sermons } \\
\text { d'Eusebius Emesenus }\end{array}$ \\
\hline $\begin{array}{l}\text { CITTÀ DEL VATICANO, Biblioteca } \\
\text { Apostolica Vaticana, Reg. lat. 131, } \\
\text { fol. } 133 \mathrm{v}^{\circ}-141 \mathrm{v}^{\circ}\end{array}$ & ca $820-830^{(\mathrm{b})}$ & France & Recueil de sermons \\
\hline $\begin{array}{l}\text { SAINT-OMER, BM, ms. 716, vol. VII, } \\
\text { fol. 197-199 }\end{array}$ & fin $\mathrm{XII}^{\mathrm{e}} \mathrm{s}$. & $\begin{array}{l}\text { abbaye } \\
\text { Clairmarais }\end{array}$ & $\begin{array}{l}\text { Légendier en } \quad 5 \text { vol. } \\
\text { conservés, sermon à la } \\
\text { suite de la Vita }\end{array}$ \\
\hline $\begin{array}{l}\text { GENÈVE, Bibl. de Genève, lat. } 24 \text {, } \\
\text { fol. } 181 \mathrm{v}^{\circ}-183 \mathrm{v}^{\circ}\end{array}$ & fin $\mathrm{XII}^{\mathrm{e}} \mathrm{s}$. & $\begin{array}{l}\text { abbayes de Fleury } \\
\text { ou de Clairvaux? }\end{array}$ & $\begin{array}{l}\text { Recueil Sermones domini } \\
\text { Eusebii }\end{array}$ \\
\hline $\begin{array}{l}\text { BRUXELLES, Bibliothèque royale de } \\
\text { Belgique, ms. } 7461 \text { (3176), } \\
\text { fol. } 96 \mathrm{v}^{\circ}-98 \mathrm{v}^{\circ}\end{array}$ & XIII ${ }^{\mathrm{e}} \mathrm{s}$. & $\begin{array}{l}\text { abbaye } \\
\text { Vaucelles }\end{array}$ & $\begin{array}{l}\text { Légendier, sermon à la } \\
\text { suite de la Vita }\end{array}$ \\
\hline
\end{tabular}

(a) A. souter, «Observations on the Pseudo-Eusebian Collection of Gallican Sermons », Journal of Theological Studies, 41 (1940), p. 47-57.

(b) J.-P. воинот, «L'homéliaire des "Sancti catholici Patres". Tradition manuscrite », Revue des études augustiniennes, 22/1-2 (1976), p. 143-185, de même pour le manuscrit de Genève. 


\section{b. $B H L-$}

Sermon LI du recueil d'Eusebius Gallicanus, attribué à Fauste. Ce Sermo in depositione sacerdotis dicendus, homilia beati Maximi episcopi, pourrait avoir été prononcé en l'honneur de Maxime ${ }^{34}$. Il a été composé après ca 461.

Éd. : EUSEBIUS GALLICANUS, Collectio Homiliarum. Sermones extravagantes, éd. F. GLORIÉ, Turnhout, 1970, LI, p. 592-603.

Tab. 2 - Les manuscrits du sermon LI.

\begin{tabular}{|c|c|c|c|}
\hline Localisation des manuscrits & Datation & Provenance & Caractéristiques \\
\hline $\begin{array}{l}\text { BERLIN, Deutsche Staatsbibliothek, } 50 \\
\text { (Phillips 1676), fol. } 299 \mathrm{v}^{\circ}-301\end{array}$ & fin VIII $-\mathrm{IX}^{\mathrm{e}} \mathrm{s}$ & $\begin{array}{l}\text { cathédrale Santa } \\
\text { Maria Matricolare } \\
\text { de Vérone }\end{array}$ & Recueil de sermons \\
\hline $\begin{array}{l}\text { BRUXELLES, Bibliothèque royale de } \\
\text { Belgique, ms. 1651-1652 (1316), } \\
\text { fol. } 61 \mathrm{v}^{\circ}-63\end{array}$ & déb. $\mathrm{IX}^{\mathrm{e}} \mathrm{s}$. & $\begin{array}{ll}\text { abbaye } & \text { de } \\
\text { Longpont? } & \end{array}$ & $\begin{array}{l}\text { Recueil de sermons } \\
\text { d'Eusebius Emesenus }\end{array}$ \\
\hline $\begin{array}{l}\text { MÜNCHEN, Bayerische Staatsbibliothek, } \\
\text { Clm } 14368 \text {, fol. } 185-187 \mathrm{~V}^{\circ}\end{array}$ & ca $820-840^{\text {(a) }}$ & $\begin{array}{l}\text { Saint-Emmeram, } \\
\text { Ratisbonne }\end{array}$ & $\begin{array}{l}\text { Recueil de sermons } \\
\text { d'Alain de Farfa }\end{array}$ \\
\hline $\begin{array}{l}\text { MÜNCHEN, Bayerische Staatsbibliothek, } \\
\text { Bayerische Staatsbibliothek, Clm } \\
4534 \text {, fol. } 230 \mathrm{v}^{\circ}-232\end{array}$ & $x^{e}-X^{e} s$ & $\begin{array}{l}\text { Germanie } \\
\text { méridionale }\end{array}$ & $\begin{array}{l}\text { Recueil de sermons de } \\
\text { Paul Diacre }\end{array}$ \\
\hline
\end{tabular}

(a) K. BIERBRAUER, Die vorkarolingischen und karolingischen Handschriften der Bayerischen Staatsbibliothek, Wiesbaden, 1990, n 118, p. 64.

\section{c. BHL 5853}

La Vita sancti Maximi est rédigée par Dynamius ${ }^{35}$ vers 580-590 et dédiée à l'évêque de Riez Urbicus - attesté en 584 et 589 - qui l'a commandée. Il s'agit vraisemblablement d'une œuvre originale. Elle combine le récit d'une vie et celui de miracula. D'après la lettre dédicatoire, elle a été composée à partir de textes de Fauste et de souvenirs rassemblés par Urbicus. Dynamius indique également avoir rédigé un texte bref en style non apprêté ( rurali sermone ») antérieurement à la Vita. Il a recouru à des témoignages locaux à propos des miracles.

Éd. : L. SURIUS, De probatis..., op. cit., p. 601-606. V. BARRALIS, Chronologia sanctorum..., op. cit., p. 120-126 [tributaire de Surius]. Patrologie latine, t. 80, Paris, 1863, col. 31-40 [qui reprend Barralis]. GCNN, t. 1, Instr., $\mathrm{n}^{\circ}$ 10, col. 370-371 [lettre dédicatoire d'après CITTÀ DEL VATICANO, Biblioteca Apostolica Vaticana, Reg. lat. 711]. Gennaro, p. 63-127. B. DUMÉZIL, « Le patrice Dynamius et son réseau : culture aristocratique et transformation des pouvoirs autour de Lérins dans la seconde moitié du VI siècle ", in Y. CODOU et M. LAUWERS (éd.), Lérins, une île sainte de l'Antiquité au Moyen Âge, Turnhout, 2009, p. 190-191 [traduction de la lettre dédicatoire de Dynamius à Urbicus]. P.-A. JACOB et P. BOULHOL (éd.), Maxime de Riez..., op. cit., p. 92-147. 
Tab. 3 - Les manuscrits de la Vita Maximi (BHL 5853-5854) ${ }^{36}$.

LN : famille du Liber de Natalitiis - LF : famille du Legendarium Flandrense - la fin de ce tableau comporte cinq manuscrits non repérés par Salvatore Gennaro.

\begin{tabular}{|c|c|c|c|c|c|}
\hline \multicolumn{2}{|c|}{$\begin{array}{l}\text { Stemma } \\
\text { (Gennaro, p. 33) }\end{array}$} & \multirow{2}{*}{ 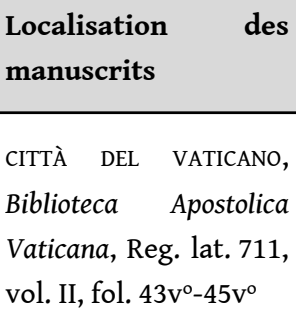 } & \multirow{2}{*}{\begin{tabular}{|l} 
Datation \\
IX $^{\mathrm{e}}$ s. (a)
\end{tabular}} & \multirow{2}{*}{$\begin{array}{l}\text { Provenance } \\
\\
\text { abbaye de } \\
\text { Fleury }\end{array}$} & \multirow{2}{*}{$\begin{array}{l}\text { Caractéristique } \\
\\
1^{\text {re }} \text { partie, avec lettre } \\
\text { dédicatoire, jusqu'à la } \\
1.269 \text { de l'éd. Gennaro }\end{array}$} \\
\hline $\mathrm{y}$ & $\mathrm{V}$ & & & & \\
\hline $\mathrm{y}$ & G & $\begin{array}{l}\text { CITTÀ DEL VATICANO, } \\
\text { Biblioteca Apostolica } \\
\text { Vaticana, Reg. lat. 274, } \\
\text { fol. } 95-97\end{array}$ & $\mathrm{IX}^{\mathrm{e}} \mathrm{s}$ & $\begin{array}{l}\text { abbaye de } \\
\text { Fleury }\end{array}$ & $2^{\mathrm{e}}$ partie, 1.269 et fin \\
\hline $\mathrm{y}$ & A & $\begin{array}{l}\text { PARIS, BnF, lat. } 3793, \\
\text { fol. } 232 \mathrm{v}^{\circ}-242 \mathrm{v}^{\circ}\end{array}$ & $\mathrm{XII}^{\mathrm{e}} \mathrm{s}$. & $\begin{array}{lr}\text { abbaye } & \text { Saint- } \\
\text { André } & \text { de } \\
\text { Villeneuve, } & \\
\text { diocèse } & \text { de } \\
\text { Sisteron }^{(b)} & \end{array}$ & Lectionnaire de l'office \\
\hline $\mathrm{y}$ & A & $\begin{array}{l}\text { CITTÀ DEL VATICANO, } \\
\text { Biblioteca Apostolica } \\
\text { Vaticana, Reg. lat. 517, } \\
\text { fol. 138-139v }{ }^{\circ}\end{array}$ & $\mathrm{XII}^{\mathrm{e}} \mathrm{s}$. & $\begin{array}{l}\text { abbaye Saint- } \\
\text { André de } \\
\text { Villeneuve?, } \\
\text { diocèse de } \\
\text { Sisteron (c) }\end{array}$ & Vita abrégée \\
\hline $\mathrm{y}$ & Q & $\begin{array}{l}\text { PARIS, BnF, lat. } 14652 \text {, } \\
\text { fol. } 162-167\end{array}$ & $\mathrm{XV}^{\mathrm{e}} \mathrm{s}$ & $\begin{array}{l}\text { abbaye Saint- } \\
\text { Victor de } \\
\text { Paris }{ }^{\text {(d) }}\end{array}$ & Légendier \\
\hline $\mathrm{y}$ & $\mathrm{R}$ & $\begin{array}{lr}\text { CITTÀ DEL } & \text { VATICANO, } \\
\text { Biblioteca } & \text { Apostolica } \\
\text { Vaticana, } & \text { Reg. lat. } \\
\text { 1864, fol. 19-26 }\end{array}$ & $\mathrm{XI}^{\mathrm{e}}-\mathrm{XII}^{\mathrm{e}} \mathrm{s}$. & $\begin{array}{lr}\text { abbaye } & \text { Saint- } \\
\text { Médard } & \text { de } \\
\text { Soissons } & \end{array}$ & $\begin{array}{l}\text { Vita sans lettre } \\
\text { dédicatoire }\end{array}$ \\
\hline $\mathrm{y}$ & 0 & 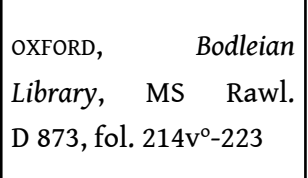 & $\begin{array}{l}\text { fin du } \\
\text { XII }^{e} s .\end{array}$ & $\begin{array}{l}\text { Reggio Emilia, } \\
\text { San Giovanni } \\
\text { Baptista juxta } \\
\text { plateam }^{(\mathrm{e})}\end{array}$ & $\begin{array}{l}\text { Hymnaire; sans lettre } \\
\text { dédicatoire }\end{array}$ \\
\hline $\mathrm{y}$ & $\mathrm{P}$ & $\begin{array}{l}\text { PARIS, BnF, lat. } 11748, \\
\text { fol. } 77 v^{0}-81\end{array}$ & $x^{e} s$ & $\begin{array}{l}\text { abbaye Saint- } \\
\text { Maur-des- } \\
\text { Fossés }^{(f)}\end{array}$ & $\begin{array}{l}\text { Légendier; Vita sans } \\
\text { lettre dédicatoire }\end{array}$ \\
\hline $\mathrm{y}$ & B & $\begin{array}{l}\text { PARIS, BnF, lat. } 17007, \\
\text { fol. } 115 v^{\circ}-118\end{array}$ & $\begin{array}{l}\text { fin du } \\
\text { XII }^{\mathrm{e}} \mathrm{s} \text {. }\end{array}$ & $\begin{array}{l}\text { abbaye Le Val- } \\
\text { Notre-Dame }{ }^{(\mathrm{g})}\end{array}$ & $\begin{array}{l}\text { Légendier LN cistercien } \\
\text { en } 5 \text { vol. }\end{array}$ \\
\hline
\end{tabular}




\begin{tabular}{|c|c|c|c|c|c|}
\hline $\mathrm{y}$ & C & $\begin{array}{l}\text { PARIS, BnF, lat. } 16735 \text {, } \\
\text { fol. } 117-120\end{array}$ & $\begin{array}{l}\text { après } \\
1190- \\
\text { XIII }^{\mathrm{e}} \mathrm{s} .\end{array}$ & $\begin{array}{l}\text { abbaye de } \\
\text { Chaalis }^{(h)} \text { puis } \\
\text { Saint-Martin- } \\
\text { des-Champs }\end{array}$ & 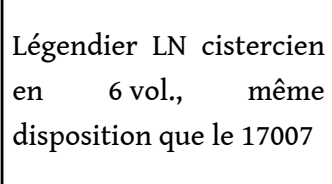 \\
\hline $\mathrm{y}$ & E & $\begin{array}{l}\text { MONTPELLIER, } B U \text { de } \\
\text { médecine, } \\
\text { fol.171-175 }\end{array}$ & $\mathrm{XII}^{\mathrm{e}} \mathrm{s}$. & $\begin{array}{ll}\text { abbaye } & \text { de } \\
\text { Clairvaux } & \end{array}$ & Légendier, vol. 1 \\
\hline $\mathrm{y}$ & $\mathrm{D}$ & $\begin{array}{l}\text { MONTPELLIER, } B U \text { de } \\
\text { médecine, } \\
\text { fol. } 240-243 \text { 30, }\end{array}$ & XII $\mathrm{s}$. & $\begin{array}{lr}\text { abbaye } & \text { Saint- } \\
\text { Bénigne }^{(} & \text {de } \\
\text { Dijon }^{(k)} & \end{array}$ & Légendier \\
\hline $\mathrm{y}$ & $\mathrm{F}$ & $\begin{array}{l}\text { PARIS, BnF, lat. } 5340 \text {, } \\
\text { fol. } 42-50\end{array}$ & $\mathrm{XI}^{\mathrm{e}} \mathrm{s}$ & $\begin{array}{l}\text { Provence pour } \\
\text { sa } \quad 1^{\text {re }} \text { partie } \\
\text { (fol. 1-129) }\end{array}$ & $\begin{array}{l}\text { Légendier; Vita sans } \\
\text { lettre dédicatoire }\end{array}$ \\
\hline $\mathrm{y}$ & W & $\begin{array}{l}\text { PARIS, } B n F \text {, nouv. acq. } \\
\text { lat. } 1522 \text {, fol. } 35 v^{\circ}-36\end{array}$ & $\begin{array}{l}\text { fin du } \\
\text { XII }^{\mathrm{e}} \mathrm{s} \text {. }\end{array}$ & $\begin{array}{l}\text { région } \quad \text { de } \\
\text { Tours ? }{ }^{(1)}\end{array}$ & $\begin{array}{l}\text { Fragment d'un recueil } \\
\text { de Vitæ acquis à Lyon; } \\
\text { Vita en partie (jusqu'à la } \\
\text { 1. } 154 \text { de l'éd. Gennaro), } \\
\text { sans lettre dédicatoire }\end{array}$ \\
\hline $\mathrm{y}$ & $\mathrm{H}$ & $\begin{array}{lr}\text { COPENHAGUE, } & \text { Det } \\
\text { Kongelige } & \text { Bibliotek, } \\
\text { Thott } 135 & \text { Fol, } \\
\text { fol. } 27-27 \mathrm{v}^{\circ} & \end{array}$ & $\mathrm{XII}^{\mathrm{e}} \mathrm{s}$. & $\begin{array}{l}\text { Collège de } \\
\text { Clermont, } \\
\text { Paris/ abbaye } \\
\text { Saint- } \\
\text { Wandrille }{ }^{(m)}\end{array}$ & $\begin{array}{l}\text { Légendier; fragment : } \\
\text { 1. } 460-581 \text { de l'éd. } \\
\text { Gennaro }\end{array}$ \\
\hline $\mathrm{y}$ & a & $\begin{array}{l}\text { CITTÀ DEL VATICANO, } \\
\text { Biblioteca Apostolica } \\
\text { Vaticana, Barb. lat. } \\
714, \text { fol. } 299 \mathrm{v}^{\circ}-303 \mathrm{v}^{\circ}\end{array}$ & XIV s. & & $\begin{array}{l}\text { Legendae de Sanctis: } \\
\text { légendier de Pietro Calò } \\
\text { OFP }(\dagger 1348) \text {, composé } \\
\text { entre } 1330 \text { et } 1340 \text { dans } \\
\text { sa rédaction } \\
\text { primitive }^{(\mathrm{n})}: \text { sans lettre } \\
\text { dédicatoire, } 1.59-574 \text { de } \\
\text { l'éd. Gennaro }\end{array}$ \\
\hline $\mathrm{y}$ & $\mathrm{b}$ & $\begin{array}{l}\text { VENEZIA, } \\
\text { Nazionale } \\
\text { Lat. IX, } 19 \text { (2946) } \\
\text { fol. 169-171vana }\end{array}$ & XIV $\mathrm{s}$. & $\begin{array}{lr}\text { Venise, } & \text { Santi } \\
\text { Giovanni } & \mathrm{e} \\
\text { Paolo OFP } & \end{array}$ & Légendier de Pietro Calò \\
\hline $\mathrm{y}$ & c & $\begin{array}{l}\text { VENEZIA, } \\
\text { Nazionale } \\
\text { Lat. IX, } 20 \text { (2947), } \\
\text { fol. 348-350v } \mathrm{v}^{\circ}\end{array}$ & XIV s. & & Légendier de Pietro Calò \\
\hline $\mathrm{y}$ & $\mathrm{d}$ & $\begin{array}{l}\text { YORK, Minster Library, } \\
\text { XVI G 23, fol. 105-106 }\end{array}$ & $\mathrm{xv}^{\mathrm{e}} \mathrm{s}$ & & $\begin{array}{l}\text { Légendier de Pietro } \\
\text { Calò, fragment }\end{array}$ \\
\hline
\end{tabular}




\begin{tabular}{|c|c|c|c|c|c|}
\hline z & I & $\begin{array}{l}\text { BRUXELLES, Bibliothèque } \\
\text { royale de Belgique, } \\
\text { ms. } 7461 \\
\text { fol. } 92 \mathrm{v}^{\circ}-96\end{array}$ & XIII $\mathrm{e}$ s. & $\begin{array}{ll}\text { abbaye de } & \text { de } \\
\text { Vaucelles } & \end{array}$ & $\begin{array}{l}\text { Légendier LF ; Vita } \\
\text { interpolée (+ BHL } 5855 \text { et } \\
\text { 5854), sans lettre } \\
\text { dédicatoire; suivi de } \\
\text { l'homélie de Fauste aux } \\
\text { fol. } 96 \mathrm{v}^{\circ}-98 \mathrm{v}^{\circ}\end{array}$ \\
\hline $\mathrm{z}$ & U & $\begin{array}{l}\text { WIEN, Österreichische } \\
\text { Nationalbibliothek, } \\
12754 \text { (9375 a), } \mathrm{n}^{\circ} 64, \\
\text { fol. } 210 \mathrm{v}^{\circ}-214 \mathrm{v}^{\circ}\end{array}$ & $\mathrm{XV}^{\mathrm{e}} \mathrm{s}$ & $\begin{array}{l}\text { archevêché de } \\
\text { Reims ? }{ }^{(p)}\end{array}$ & $\begin{array}{l}\text { Recueil de vies de saints, } \\
\text { Vita interpolée }\end{array}$ \\
\hline z & $\mathrm{M}$ & $\begin{array}{l}\text { DOUAI, BM, ms. } 838 \\
\text { fol. } 120 \mathrm{v}^{\circ}-122 \mathrm{v}^{\circ}\end{array}$ & XIII ${ }^{\mathrm{e}} \mathrm{s}$. & $\begin{array}{l}\text { abbaye de } \\
\text { Marchiennes }\end{array}$ & \begin{tabular}{|lrr} 
Légendier & LF & Vita \\
interpolée, & sans lettre \\
dédicatoire & &
\end{tabular} \\
\hline $\mathrm{z}$ & M & $\begin{array}{l}\text { DOUAI, BM, ms. } 855 \text {, } \\
\text { fol. } 80 \mathrm{v}^{\circ}-93\end{array}$ & $\mathrm{Xv}^{\mathrm{e}} \mathrm{s}$ & $\begin{array}{l}\text { abbaye } \\
\text { d'Hasnon }^{(r)}\end{array}$ & $\begin{array}{lrr}\text { Légendier } & \text { LF } ; & \text { Vita } \\
\text { interpolée, } & \text { sans lettre } \\
\text { dédicatoire } & & \end{array}$ \\
\hline z & S & $\begin{array}{ll}\text { SAINT-OMER, } & \text { BM, } \\
\text { ms. 716, } & \text { t. 8, } \\
\text { fol. 193-197 } & \end{array}$ & XIII $\mathrm{s}$. & $\begin{array}{l}\text { abbaye de } \\
\text { Clairmarais }{ }^{(s)}\end{array}$ & $\begin{array}{l}\text { Légendier LF ; Vita } \\
\text { interpolée suivie de } \\
\text { l'homélie de Fauste } \\
\text { attribuée à Eusebius aux } \\
\text { fol.197-199; sans lettre } \\
\text { dédicatoire }\end{array}$ \\
\hline $\mathrm{z}$ & $\mathrm{T}$ & $\begin{array}{l}\text { SAINT-OMER, } \\
\text { ms. } 746, \text { t. } 2 \\
\text { fol. } 17-23^{\text {bis }}\end{array}$ & $\mathrm{XVII}^{\mathrm{e}} \mathrm{s}$. & $\begin{array}{l}\text { abbaye Saint- } \\
\text { Bertin }\end{array}$ & $\begin{array}{llr}\begin{array}{l}\text { Légendier } \\
\text { interpolée, }\end{array} & & \text { Copie } \\
\text { moderne } & & \end{array}$ \\
\hline $\mathrm{z}$ & $\mathrm{Z}$ & $\begin{array}{ll}\text { SAINT-OMER, } & \text { BM, } \\
\text { ms. 715, } & \text { t. 4, } \\
\text { fol. 132-136 } & \end{array}$ & XIII ${ }^{\mathrm{e}}$ s. & $\begin{array}{l}\text { chapitre de } \\
\text { Saint-Omer }\end{array}$ & $\begin{array}{lrr}\text { Légendier } & \text { LF } & \text { Vita } \\
\text { interpolée, } & \text { sans } & \text { lettre } \\
\text { dédicatoire } & & \end{array}$ \\
\hline z & $\mathrm{f}$ & $\begin{array}{l}\text { WIEN, Österreichische } \\
\text { Nationalbibliothek, Ser. } \\
\text { n. } 12812 \text { (9397 a), II, } \\
\text { fol. } 98-99 v^{\circ}\end{array}$ & $\mathrm{XV}^{\mathrm{e}} \mathrm{s}$ & $\begin{array}{l}\text { prieuré de } \\
\text { Rouge-Cloître } \\
\text { ou de } \\
\text { Corsendonk }\end{array}$ & $\begin{array}{l}\text { Jean Gielemans ( } † \text { 1487), } \\
\text { Sanctilogium, vol. } 2 \\
(\text { BHL nov. suppl. 9042): } \\
\text { Vita interpolée; source } \\
\text { possible: légendier de } \\
\text { l'abbaye des Dunes } \\
\left(\mathrm{xv}^{\mathrm{e}} \mathrm{s.}\right)^{(\mathrm{t})}\end{array}$ \\
\hline & $\mathrm{N}$ & $\begin{array}{l}\text { ROUEN, BM, ms. } 1397 \\
\text { (U 141), fol. 186-191vo }\end{array}$ & XII ${ }^{\mathrm{e}}$ s. & $\begin{array}{ll}\text { abbaye de } \\
\text { Jumièges }(\mathrm{u})\end{array}$ & $\begin{array}{l}\text { Légendier, Vita sans } \\
\text { lettre dédicatoire }\end{array}$ \\
\hline y & & $\begin{array}{l}\text { DIJON, BM, ms. } 642 \\
(383), \text { fol. } 33\end{array}$ & $\begin{array}{l}\text { fin } \mathrm{XI}^{\mathrm{e}} \text { s.- } \\
\text { déb. } \mathrm{XII}^{\mathrm{e}} \mathrm{s} \text {. }\end{array}$ & $\begin{array}{l}\text { abbaye de } \\
\text { Cîteaux }^{(v)}\end{array}$ & $\begin{array}{l}\text { Légendier, vol. } 5 \text {; sans } \\
\text { lettre dédicatoire }\end{array}$ \\
\hline
\end{tabular}




\begin{tabular}{|c|c|c|c|c|}
\hline $\mathrm{y}$ & $\begin{array}{l}\text { LINCOLN, } \quad \text { Cathedral, } \\
\text { MS 107 } \\
\text { fol. } 42-49\end{array}$ & $\begin{array}{l}\text { fin du } \\
\mathrm{XII}^{\mathrm{e}} \mathrm{s} \text {. }\end{array}$ & $\begin{array}{l}\text { cathédrale de } \\
\text { Lincoln, sous } \\
\text { l'évêque Hugues } \\
\text { d'Avalon } \\
(1186-1200)^{(\text {w) }}\end{array}$ & $\begin{array}{llr}\text { Recueil de } & \text { vies } \\
\text { d'évêques; avec lettre } \\
\text { dédicatoire }\end{array}$ \\
\hline & $\begin{array}{l}\text { AVIGNON, Médiathèque } \\
\text { Ceccano, ms. } 219 \text {, } \\
\text { fol. } 242 \mathrm{v}^{\circ}-244 \mathrm{v}^{\circ}\end{array}$ & ca $1340-1370$ & $\begin{array}{l}\text { chapitre Sainte- } \\
\text { Marie du Bourg } \\
\text { de Digne }^{(\mathrm{x})}\end{array}$ & 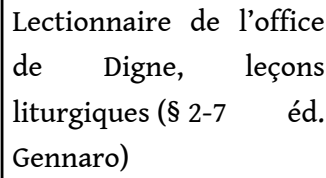 \\
\hline & $\begin{array}{l}\text { DRAGUIGNAN, BM, ms. } 3 \\
\text { (R6), fol. } 132 \mathrm{v}^{\circ}-134\end{array}$ & $x^{e} s$ & $\begin{array}{l}\text { chapitre Saint- } \\
\text { Maxime de } \\
\text { Riez }^{(y)}\end{array}$ & $\begin{array}{l}\text { Bréviaire de Riez, leçons } \\
\text { liturgiques } \quad \text { (§ 2-6 éd. } \\
\text { Gennaro) }\end{array}$ \\
\hline
\end{tabular}




\begin{tabular}{|l|l|l|l|l|}
\hline & $\begin{array}{l}\text { CHARTRES, BM, ms. } 115 \\
(63), \text { fol. } 43 \mathrm{v}^{\circ}-55 \mathrm{v}^{\mathrm{o}}\end{array}$ & $\mathrm{IX}^{\mathrm{e}}-\mathrm{X}^{\mathrm{e}} \mathrm{s}$. & $\begin{array}{l}\text { Chartres, Saint- } \\
\text { Père-en-Vallée } \\
\text { OSB ? }{ }^{(\mathrm{z})}\end{array}$ & $\begin{array}{l}\text { Mutilé, auj. perdu ; avec } \\
\text { lettre dédicatoire }\end{array}$ \\
\hline
\end{tabular}


(a) A. PONCELET, Catalogus codicum hagiographicorum latinorum bibliothecæ Vaticanæ, Bruxelles, 1910, p. $398,311,408$ et 346.

(b) La présence de la Vita Donati au folio 196v (BHL 2310 ; PARIs, BnF, lat. 3793 ; Catalogus codicum hagiographicorum latinorum antiquiorum saeculo xvı qui asservantur in Bibliotheca nationali Parisiensi, t. 1, Paris/Bruxelles, 1889, p. 309-313) permet à François Dolbeau d'émettre cette hypothèse : F. DolBEAu, "Anciens possesseurs des manuscrits hagiograhiques latins conservés à la bibliothèque nationale de Paris », Revue d'histoire des textes, 9 (1979), p. 193. II semble que la Vita Maximi ait été assimilée dans ce manuscrit à une commande pontificale comme en témoigne l'incipit (fol. 232vº-233) : Incipit prologus Dinamii patricii ad romanum papam in vita beati Maximi Regensis civitatis episcopi.

(c) À rapprocher du Paris, BnF, lat. 3793 : F. Dolbeau « Anciens possesseurs... », ibid., p. 193, n. 2. Outre celle de Donat (BHL nov. sup. $2310^{\text {b }}$; città del vaticano, Biblioteca Apostolica Vaticana, Reg. lat. 517 , fol. 1-1V ; A. Poncelet, Catalogus codicum..., op. cit., p. 532-534), les Vitæ de Thyrse et de Mary vénérés à Sisteron et Forcalquier, aux côtés de celles d'autres saints provençaux rhodaniens, paraissent étayer l'hypothèse mentionnée dans la note précédente. T. PÉcout, Martyrologes de Provence, à paraître. (d) G. our, Les manuscrits de l'abbaye de Saint-Victor. Catalogue établi sur la base du répertoire de Claude de Grandrue (1514), t. 2, Turnhout, 1999, p. 477-478.

(e) G. D. macray, Catalogi codicum manuscriptorum bibliothecæ Bodleianæ, t. 5-4, Oxford, 1898, col. 52-53. A. meRCATI, «Per la storia letteraria di Reggio Emilia », in Saggi di storia e letteratura, t. 1, Rome, 1951, p. 100-102.

(f) Catalogus codicum hagiographicorum..., op. cit., t. 3 (1893), p. 4 ; t. 2 (1890), p. 262 ; t. 1 (1889), p. 305 et t. 3 (1893), p. 349, 396 et 271

(g) F. DolbeAu « Anciens possesseurs... », op. cit., p. 230 ; ID., « Notes sur la genèse et sur la diffusion du Liber de Natalitiis », Revue d'histoire des textes, 6 (1976), p. 163. A. BONDÉELLE-SOUCHIER, Bibliothèques cisterciennes dans la France médiévale. Répertoire des abbayes d'hommes, Paris, 1991, p. 189 et 249-256. (h) F. Dolbeau «Anciens possesseurs... », ibid., p. 230. Pour la datation, voir ID., « Notes sur la genèse... », ibid., p. 158

(j) H. MORETUs, « Catalogus codicum hagiographicorum latinorum bibliothecæ scolæ medicinæ in universitate Montepessulanensi », Analecta Bollandiana, 34-35 (1915-1916), p. 230.

(k) H. MORETus, « Catalogus codicum... », ibid., p. 246.

(I) Ce recueil comporte de nombreux textes concernant Martin de Tours, d'œuvres de Sulpice Sévère ou de Grégoire de Tours : cela suffit-il pour y voir une compilation élaborée dans la région du confesseur tourangeau ? L. DELISLE, Manuscrits latins et français. Accroissement des fonds de la Bibliothèque nationale, Paris, 1891, p. 660-662. Ce fragment de la Vita Maximi s'achève au § 6, I. 154, p. 81 (selon l'édition de Salvatore Gennaro).

(m) E. JØRGEnsen, Catalogus codicum latinorum medii ævi bibliothecæ regiæ Hafniensis, Copenhague, 1926, p. 197-199. S. cavaluin, «Eine neve Handschrift der Vita Caesari Arelatensis », Bulletin de la Société royale des lettres de Lund (1935-1936), p. 9-27, part. p. 15-19. II se peut que le manuscrit Thott 133 Fol (saints des mois de juin, juillet, août) ait connu la même histoire que le Thott 135 Fol, concernant les saints de la fin de l'année, évoqué par B. DE GAIFFIER, «Le passionnaire du collège de Clermont conservé à Copenhague », Speculum, t. 5 (1951), p. 20-25 [repris dans B. DE GAIFFIER, Études critiques d'hagiographie et d'iconologie, Bruxelles, 1967, p. 394-400].

(n) A. poncelet, «Le légendier de Pierre Calo », Analecta Bollandiana, 29 (1910), p. 5-116, ici p. 30-35, 95 et 106. C. gennaro, s. v. «Calò Pietro », in Dizionario degli Italiani, t. 16, Rome, 1973, p. 787-789.

(o) Catalogus codicum hagiographicorum bibliothecæ regiæ Bruxellensis, t. 1-2, Bruxelles, 1889, p. 15.

J. vAN DEN GHEYN, Catalogue des manuscrits de la bibliothèque royale de Belgique, t. 5 (Histoire et hagiographie), Bruxelles, 1905, p. 139. W. LEvISON, «Conspectus codicum hagiographicorum », in MGH, Scriptores rerum Merovingicarum, t. 7 (Passiones vitaeque sanctorum aevi Merovingici), éd. B. кRusch et W. LEVISON, Hanovre/Leipzig, 1920, p. 564.

(p) «Catalogus codicum hagiographicorum qui Vindobonæ asservantur in bibliotheca privata Serenissimi Cæsaris Austriaci », Analecta Bollandiana, 14 (1895), p. 254. On y rencontre nombre de vies de saints des pays belges et de l'archevêché de Reims.

(q) «Catalogus codicum hagiographicorum latinorum bibliothecæ publicæ Duacensis », Analecta Bollandiana, 20 (1901), p. 391.

(r) « Catalogus codicum hagiographicorum... », ibid., p. 410.

(s) R. LECHAT, « Catalogus codicum hagiographicorum latinorum bibliothecæ publicæ Audomaropolitanæ», Analecta Bollandiana, 47 (1929), p. 265, 283 et 286. S. staAts, Le catalogue médiéval de l'abbaye cistercienne de Clairmarais et les manuscrits conservés, Paris, 2016, p. 69-70.

(t) Cette compilation a été composée dans les années 1470. De codicibus hagiographicis lohannis Gielemans canonici regularis in Rubea Valle prope Bruxellas adiectis anecdotis, Bruxelles, 1895 [extrait d'Analecta Bollandiana, 14 (1895), p. 5-88]. L'une des sources utilisées par le chanoine de Windesheim est le légendier perdu de Gilles de Damne († ca 1463), de l'abbaye cistercienne des Dunes. E. PERsoons, s. v. « Jean Gielemans », in Dictionnaire d'histoire et de géographie ecclésiastiques, t. 20, Paris, 1984, col. 1256-1257.

(u) «Catalogus codicum hagiographicorum latinorum bibliothecæ publicæ Rotomagensis », Analecta Bollandiana, 23 (1904), p. 129-275.

(v) A. molinier, H. omont et al., Catalogue général des manuscrits des bibliothèques publiques de France. 
Départements, t. 5 (Dijon), Paris, 1889, p. 166-181.

(w) R. M. wooler, Catalogue of the Manuscripts of Lincoln Cathedral Chapter Library, Londres, 1927, p. 70-71. R. M. тhompson, Catalogue of the Manuscripts of Lincoln Cathedral Chapter Library, Cambridge, 1989, p. 80-81.

${ }^{(x)}$ L.-H. LABANDE, Catalogue général des manuscrits des bibliothèques publiques de France. Départements, t. 22 (Avignon), Paris, 1894, p. 127-128. T. DEsBonnets, «La diffusion du culte de saint François d'Assise en France d'après les bréviaires manuscrits étrangers à l'ordre ", Archivum Franciscanum historicum, t. 75 (1982), p. 179. T. pécout, « De Saint-Cannat à Saint-Cannat. Les résidences de l'évêque de Marseille, xII-xIV siècle», Provence historique, 66 (2016), p. 345-366, n. 75. T. PÉcout, « Le culte de Marcellin d'Embrun », à paraître.

(y) J. H. alBanès, Catalogue général des manuscrits des bibliothèques publiques de France. Départements, t. 14 (Clermont-Ferrand, Caen, Toulon, Draguignan, Fréjus, Grasse, Nice, Tarascon), Paris, 1890, p. 397 ; V. LeRoquals, Les bréviaires manuscrits des bibliothèques publiques de France, t. 2, Mâcon, 1934, n² 254, p. 80-82.

(z) C. DE SMEDT, « Catalogus codicum hagiographicorum latinorum bibliothecæ civitatis Carnotensis », Analecta Bollandiana, 8 (1889), p. 93. H. омоNт, A. molinier et al., Catalogue général des manuscrits..., op. cit., t. 11 (Chartres), Paris, 1890, p. 62-63. B. KRUscH, « Reise nach Frankreich im Frühjahr und Sommer 1892 », Neues Archiv der Gesellschaft für Altere Deutsche Geschichtskunde, 18 (1893), p. 570-571, qui n'a relevé que la Vita de Mesmin de Micy (BHL 5814-5816 et 5817, toutes deux du Ix ${ }^{\mathrm{e}}$ siècle). W. LEvison, "Conspectus codicum hagiographicorum », in MGH, Scriptores rerum Merovingicarum, t. 7 (Passiones vitaeque sanctorum aevi Merovingici), éd. B. кRUsch et W. Levison, Hanovre/Leipzig, 1920, p. 575.

C'est par inadvertance que Jean-Claude Moulinier signale la Vita de Maxime de Riez dans le manuscrit PARIS, $B n F$, lat. 3789 , fol. $67 \mathrm{v}^{\circ}-79 \mathrm{v}^{\circ}$. Ce légendier, provenant de la collégiale Saint-Aignan d'Orléans et datant en partie du $\mathrm{XI}^{\mathrm{e}}$ siècle, rapporte la Vita Maximi abbatis Miciacensis ${ }^{37}$.

Un recueil de vies de saints des $\mathrm{X}^{\mathrm{e}}$ et $\mathrm{XI}^{\mathrm{e}}$ siècles signale dans sa table la présence de la Vita Maximi, aujourd'hui manquante ${ }^{38}$. Quatre légendiers perdus comportaient aussi la Vita Maximi ${ }^{39}$. Il s'agit tout d'abord de ceux de La Charité - diocèse de Besançon, fondée en 1133, filiation de Bellevaux et Morimond - et de Longpont - diocèse de Soissons, fondée en 1132, filiation de Clairvaux - , abbayes cisterciennes ${ }^{40}$. La première est située dans la haute vallée de la Saône, la seconde au sud de Soissons. Selon François Dolbeau, le recueil de La Charité peut être rapproché de celui de Notre-Dame d'Acey établissement cistercien du diocèse de Besançon fondé en 1136, filiation de Cherlieu et Clairvaux -, également perdu et correspondant à un état primitif du légendier de Cîteaux ${ }^{41}$. Ce légendier mentionnait aussi la Vita Maximi au 27 novembre ${ }^{42}$. Il s'agit de collections appartenant à un groupe bourguignon et franc-comtois de sources du Liber de Natalitiis ${ }^{43}$. Le légendier de Longpont, partiellement dérivé du Liber de Natalitiis, paraissait aussi receler des similitudes avec les collections de Saint-Omer ${ }^{44}$. Les recueils conservés de Chaalis - 1137, filiation de Pontigny - et du Val - 1125, filiation de La Cour-Dieu - constituent des formes proprement dites du Liber de Natalitiis. La Vita Maximi est aussi attestée dans un recueil de l'établissement prémontré Notre-Dame et Saint-Yvred de Braine constitué au XIII ${ }^{\mathrm{e}}$ siècle ${ }^{45}$. Enfin, les premiers éditeurs de la Vita sous sa forme abrégée BHL 5856, Lorenz Sauer et Vincent Barralis, semblent avoir consulté un même manuscrit, vraisemblablement d'origine lérinienne ${ }^{46}$.

De surcroît, la bibliothèque de Dijon conserve un manuscrit de la Vita Maximi non repéré par la critique et provenant de l'abbaye de Cîteaux ${ }^{47}$. Ce légendier est composé dans le premier tiers du XII ${ }^{\mathrm{e}}$ siècle. Ne comportant ni prologue de Dynamius ni interpolation de Thérouanne, il pourrait se rattacher aux manuscrits de la famille $y$. La cathédrale de Lincoln recèle également un recueil de vies de saints évêques de cent dixneuf folios contenant la Vita Maximi parmi d'autres modèles pastoraux édifiants, à la sainteté ancienne comme Nicolas de Myre par Jean Diacre (IX siècle), Cyprien de Carthage, Hilaire de Poitiers par Venance Fortunat, Martin de Tours par Sulpice Sévère, 
Honorat d'Arles par Hilaire, ou plus récente tels Malachie archevêque d'Armagh († 1148) par Bernard de Clairvaux et Hugues de Grenoble († 1132) $)^{48}$. Tous entretiennent d'étroites relations avec le monachisme. En outre, ils semblent ici s'intégrer à un propos d'inspiration cistercienne et modèlent une figure d'évêque idéal selon ce mouvement. Composé vers la fin du XII ${ }^{\mathrm{e}}$ siècle pour l'évêque chartreux Hugues d'Avalon (1186-1200), il pourrait avoir été déposé à la cathédrale de Lincoln dès la fin de son pontificat ${ }^{49}$. Hugues a administré durant sa jeunesse la cella Sancti Maximi près de Villardbenoît et semble avoir nourri pour ce saint une spéciale dévotion : sa Vita en fait un «Regentium nobilis patronus ». Lors du voyage effectué par Hugues vers 1199 sur les lieux de sa jeunesse, l'évêque de Lincoln visite son ancienne cella et rapporte des reliques de son périple ${ }^{50}$. Il a pu faire consigner cette Vita Maximi à cette occasion. La Vita Maximi occupe les folios 42-49, elle vient après la Vita Sancti Cipriani par l'archidiacre Pons et avant la Vita Martini de Sulpice Sévère (BHL 5610). La Vita Maximi de Lincoln ne comporte pas les interpolations destinées à justifier la venue de Maxime à Thérouanne. Elle rassemble le prologue dédicatoire, les vingt et un chapitres selon la numérotation adoptée par Salvatore Gennaro, à l'exclusion des 17a - épisode des diacre et sous diacre Valerius et Rusticus - et 19a - extrait de Grégoire de Tours, BHL 5855. Ces éléments incitent à la rattacher à un archétype méridional plutôt qu'aux traditions de Thérouanne ou de Normandie. Le recueil d'Hugues de Lincoln caractérise un modèle épiscopal promu par une génération imprégnée par les idéaux monastiques et le renouveau cistercien ${ }^{51}$.

On dispose de quelques autres jalons de la Vita Maximi, évêque de Riez et patron de Thérouanne, consignés aux temps modernes. La bibliothèque royale de Belgique conserve dans les Collectanea bollandiana un dossier hagiographique constitué par les Bollandistes aux XVII ${ }^{e}$ et XVIII ${ }^{e}$ siècles : BRUXELLES, Bibliothèque royale de Belgique [Koninklijke Bibliotheek van België], ms. 8957-58 (3512), fol. 60-113v ${ }^{052}$. À côté d'une Vita de Maxime de Vienne (fol. 61-62), le dossier se compose de plusieurs recensions de la Vita Maximi à partir de manuscrits transmis en grande partie par le jésuite Pierre-François Chifflet, d'un relevé de notices martyrologiques (fol. 97-97 ${ }^{\circ}$ ), des récits du transfert des reliques de Boulogne à Thérouanne en $1133\left(\right.$ fol. 66-66 $\left.\mathrm{v}^{\circ}\right)$ et de la translation de 1085 à Nantua (fol. 112-113v ). Cette Vita est également présente dans un recueil de la fin du XVII ${ }^{\mathrm{e}}$ siècle rassemblant des sources sur l'histoire de Boulogne-sur-Mer : PARIS, $B n F$, lat. 11066, fol. 146-156. Elle est aussi suivie aux folios $156 v^{\circ}-159$ du récit de la récupération des reliques de Maxime en 1133, de même pour la Vita conservée dans le fonds de Picardie de la Bibliothèque nationale de France - voir infra le détail de ces recensions tardives. Ces leçons se rattachent aux manuscrits de la famille $z$.

\section{d. $B H L 5855$}

Miracle de guérison d'un petit enfant accompli sur la tombe de Maxime et rapporté par Grégoire de Tours ( $† 594)$, vers $587-588^{53}$. Ce récit est intégré à la Vita Maximi dans sept de ses manuscrits, de la famille $z$ [BRUXELLES, Bibliothèque royale de Belgique, ms. 7461 ; WIEN, Österreichische Nationalbibliothek, 12754 ; DOUAI, BM, ms. 838 et 855 ; SAINT-OMER, BM, ms. 716, 746 et 715].

Éd. : GRÉGOIRE DE TOURS, Libri miraculorum, VIII, In Gloria confessorum, 82, in MGH, Scriptores rerum Merovingicarum, t. 1, Gregorii Turonensis opera, éd. B. KRUSCH et W. LEVISON, Hanovre, 
1885, p. 350-351. Gennaro, § 19a, p. 120-122. P.-A. JACOB et P. BOULHOL (éd.), Maxime de Riez..., op. cit., p. 148-149.

\section{e. $B H L 8679<B H L 5853$}

Vita de Virgile, « archevêque » d'Arles, composée entre le début du viI ${ }^{\mathrm{e}}$ et le milieu du $\mathrm{VIII}^{\mathrm{e}}$ siècle, et reprenant, en l'adaptant, le texte de la Vita Maximi ${ }^{54}$.

PARIS, BnF, lat. 5295, fol. 93-100v ${ }^{\circ}$, addition du XII ${ }^{\mathrm{e}}$ siècle dans l'unique manuscrit des $\mathrm{XI}^{\mathrm{e}}-$ $\mathrm{XII}^{\mathrm{e}}$ siècles provenant de la chapelle épiscopale d'Arles ${ }^{55}$. Le recueil rassemble d'abord le sermon d'Hilaire sur Honorat, les Vitce d'Hilaire et de Césaire, ainsi que des pièces un peu plus tardives, sermons sur Trophime, Vita de ce dernier, Vita Reguli.

Éd. : AA SS martii, t. 1, Paris/Rome, 1865, p. 399-402. MGH, Scriptores rerum Merovingicarum, t. 4, éd. B. KRUSCH, Hanovre/Leipzig, 1902, p. 337-451.

Ind. : S. GENNARO, « La Vita S. Maximi ep. Reiensis e la Vita S. Virgilii ep. Arelatensis », Annuario 1964-1965 del Liceo-Ginnasio Mario Cutelli (1966), p. 61-66. S. GIOANNI, « La "Vita Virgilii" (BHL 8679) : plagiat, réécriture ou remploi ? ", in M. GOULLET, M. HEINZELMANN et C. VEYRARD-COSME (éd.), L'hagiographie mérovingienne à travers ses réécritures, Paris, 2010, p. 125-159. E. MAGNANI, « Trophimus, Dionisus, Regulus, Felicissimus... Listes et vies des premiers évêques d'Arles (IX ${ }^{\mathrm{e}}$-XII ${ }^{\mathrm{e}}$ siècle) », Provence historique, 66 (2016), p. 103-118. T. PÉCOUT, Le livre du chapitre du chapitre cathédral Notre-Dame de la Seds de Toulon, Paris, 2020 , p. 59 (n. 1), 370 (n. 3) et 382 (n. 2).

\section{f. $B H L 5856$}

Variantes abrégées de la Vita, attribuées à Dynamius, élaborées et diffusées en Italie du nord. La première forme correspond à la partie centrale de la Vita Maximi - 1.59-574 de l'éd. S. Gennaro - et a été transmise par le légendier de Pietro Calò OFP († 1348), composé entre 1330 et 1340 dans sa rédaction primitive ${ }^{56}$. Elle omet la lettre dédicatoire à Urbicus et le préambule, ainsi qu'exhortation et invocation finales. Une version beaucoup plus brève est diffusée par Pietro de' Natali, évêque d'Equilio († apr. 1400) dans son recueil rédigé vers 1370 à partir du légendier de Pietro Calò.

- Legendoe de Sanctis, légendier de Pietro Calò.

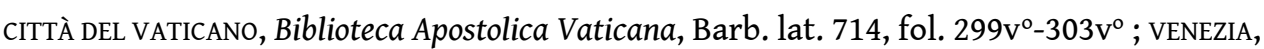
Biblioteca Nazionale Marciana, Lat. IX, 19 (2946), fol. 169-171v ${ }^{\circ}$ et Lat. IX, 20 (2947), fol. 348-350v ; YORK, Minster Library, XVI G 23, fol. 105-106 (fragment).

Éd. : Gennaro, p. 71-126. P.-A. JACOB et P. BOULHOL (éd.), Maxime de Riez..., op. cit., p. 96-138. Inc. : « De sancto Maximo episcopo. Maximus qui fuit Regensis episcopus vico proprio qui dicitur Decomato ortus parentibus christianis factus est ilico christianus qui ab infantie » [...], Expl. : [...] « sicut sibi predictum retullit hujus vite cursum amisit quare non valuit differre terminum nec silere misterium ».

- Catalogus sanctorum de Pietro de' Natali.

PIETRO DE' NATALI, Catalogus sanctorum et gestorum eorum ex diversis voluminibus collectus, lib. VIII, cxxxi, Lyon, 1506, fol. 196vº-197 ; Lyon, 1514, fol. 222vo-223 ; Lyon, 1543, 
fol. $171 \mathrm{v}^{0}$ - le texte est absent de l'édition de Vicenza, 1493. V. BARRALIS, Chronologia sanctorum..., op. cit., p. 127-128.

Inc. : « Maximus episcopus apud Rhegynem civitatem claruit » [...], Expl. : [...] « sicque sepultus est in ecclesia Sancti Petri Rhegyne civitatis ubi jacet miraculis clarus ».

\section{g. Les chapitres Saint-Maxime de Riez et Sainte-Marie de Vernon}

\section{g-1. Lettre à Richard, évêque d'Évreux}

Lettre de l'évêque de Riez Rostaing de Sabran, évêque de Riez, et son chapitre, à Richard, évêque d'Évreux, le 14 mai 1232, sur la requête de Nicolas, doyen de la collégiale Sainte-Marie de Vernon.

- CARPENTRAS, Bibliothèque Inguimbertine, ms. 706, recueil de notes diverses sur les Églises de Provence, $\mathrm{XVIII}^{\mathrm{e}}$ siècle : fol. 449, De saint Maxime évêque de Riez, ancien patron de l'Église de Téroüenne [en marge :] "par le P. Le Quien, dominicain ${ }^{57}$; fol. 449bis, notule où se trouve la lettre.

- PARIS, BnF, lat. 11066, recueil de pièces sur l'histoire de Boulogne par Jacques Prevost, fol. $139 \mathrm{v}^{\circ}$, à partir d'une copie collationnée par Jean Théroude.

Éd. : Bartel, p. 200-201, d'après une copie sur l'original en parchemin dressée en 1632 par le chanoine de Vernon Le Maire.

Venerabili in Christo patri ac domino Richardo ${ }^{(a)}$ Dei gratia Ebroicensi episcopo, Rostagnus ${ }^{(b)}$ Dei permissione episcopus et totum capitulum Regense omnimodam reverentiam cum salute. Paternitatis vestræ literas recepimus qua decuit reverentia et honore socios nostros et amicos charissimos Nicolaum (c) decanum ecclesiæ sanctæ Mariæ Vernonensis (d) ejusque socios tractantes cum benevolentia et charitate quantum honestas permisit, in suis petitionibus exauditos. Quia vero de reliquiis gloriosissimi patroni nostri Maximi nisi caput non habemus ${ }^{(e)}$ et brachium argento inclusa vos super his dandis non potuimus exaudire. Verum de vestibus ejus viri et minus ossulum brachii beatissimæ et apostolicæ virginis et martyris Theclæ ${ }^{(f)}$ apostoli Pauli discipulæ et contemporaneæ, ecclesiæ Vernonensi per viros venerabiles memoratos vestræ magnitudinis precibus et ipsorum in societatis et amicitiæ augmentum initimus, cæteræ quæ de gloriosissimo confessore Maximo didicerunt viva voce vobis poterunt aperire, verum nos paratos semper ad beneplacitum vestrum poteritis invenire. Datum Regii incarnationis Dominicæ anno millesimo ducentesimo trigesimo secundo II idus maii.

(a) Richard OSB, abbé du Bec-Hellouin en 1211, évêque d'Évreux (1223-1236), attesté à Gisors en mai $1232^{58}$.

(b) Rostaing de Sabran, évêque de Riez (ca 1225-1240).

(c) Nicolas, doyen du chapitre de Notre-Dame de Vernon : un chanoine de ce nom est signalé dès 1228, sans doute identique au chanoine Nicolas Strabo paraissant entre 1217 et 1221, puis au doyen Nicolas signalé en 1233 et 1237, cf. L. DELISLE, Cartulaire normand de Philippe Auguste, Louis VIII, saint Louis et Philippe le Hardi, Caen, 1852, no 1126 [add. 306], 709 (n. 1), 306, 341 et 374.

(d) Vernon, dép. de l'Eure, ch.-l. canton.

(e) PARIS, BnF, lat. 11066, prae manibus inséré ici.

(f) Thècle vierge est vénérée comme patronne de la cité de Riez au 23 septembre ; son culte est attesté dès 1289 , une tour de la ville porte son nom au moins depuis 1397 et l'église du castrum de La Roquette (com. de Montmeyan, dép. du Var) lui est dédiée, cf. E. LANGLoIs, Les registres de Nicolas IV : recueil de bulles de ce pape publiées ou analysées d'après les manuscrits originaux du Vatican, t. 1, Paris, 1905, $\mathrm{n}^{\circ} 1414$; J.-J.-M. FÉRAUD, Les saints tutélaires de l'église de Riez ou vies des saints évêques 
Maxime et Fauste et de sainte Thècle, Digne, 1850; G. DE MANTEYER, La Provence du premier au douzième siècle. Étude d'histoire et de géographie politique, Paris, 1908, p. 185-195. On trouve également une église vouée à Thècle dans le diocèse de Nice, à Peillon, attestée le 6 mai 1206 (Alpes-Maritimes; Codex diplomaticus ordinis Sancti Rufi Valentiae, éd. U. CHEVALIER, Valence, 1891, nº 94, p. 102-108).

\section{g-2. Lettre au chapitre de Sainte-Marie de Vernon}

Rostaing de Sabran, évêque de Riez, au chapitre de Sainte-Marie de Vernon représenté par son doyen et deux chanoines, le [8 ou 9 ?] mai 1232.

- PARIS, BnF, lat. 11066, fol. 140-142 $\mathrm{v}^{\mathrm{o}}$ [copie de la fin du XVII ${ }^{\mathrm{e}}$ siècle, sur une transcription de Jean Théroude].

Éd. : J. THÉROUDE, Epistolce quaedam de amicitia olim contracta a diversiis ecclesiis, propter sanctum Maximum episcopum Regii in Provincia, Paris, 1636, p. 5-9, copie du 5 mars 1632 d'après une lettre manuscrite - « ex originali in manbrano scripto » - alors conservée dans les archives de la collégiale. Cette édition ne comprend pas la première phrase. Bartel, p. 196-200, d'après une copie du manuscrit original dressée par le chanoine Le Maire en 1632 .

[Viris venerabilibus et dilectis in Christo fratribus et amicis Nicolao decano vestro et capitulo ecclesie Beate Marie Vernonis, Rostagnus miseratione divina episcopus et totum capitulum Regense, firmamentum stabilitatis constantiæque ejus quam in amicitia quærimus (a), cum salute.] Quanta cordis et totius animi jucunditate in Domino nostrae humilitas parvitatis exultaverit viris venerabilibus Nicolao decano et Mauritio et Joanne Britone receptis cum vestris litteris et devotione vestra acceptissima quæ usquequaque gloriossimi patris ac patroni nostri sanctissimi Maximi nostræ scilicet Regensis ecclesiæ olim indubitanter antistitis, se suamque patriam reliquiarum corporis sacrosancti ejusdem præsentiæ patrocinio illustrata et miraculorum frequentia ubere gloria gloriatur, etiam si lingua carnis explicare non sufficiat. Novit ille omnium testis [infaillibiliter] qui abyssos intuetur scrutator cordium $^{(b)}$, qui novit etiam [omnia] antequam fiant, summus ille rerum opifex cujus misericordiæ dono vidua sanctissimi confessoris vere Maximi /fol. 140vo/ utrorumque patroni meritis meruit moerore spiritu repulso, indui pallio gaudii ex umbris mortis pallentibus eidem filia restituta. Sane fraternitatis ex omni parte in uno capite Jesu Christo vobis nobisque tanquam membris honore indissolubili charitatis compactis glutino ${ }^{(c)}$ contrahendo, unum corpus effici per pretiosissimi thesauri corporis reliquiarum beatissimi confessoris Maximi pignus ut postulastis piis satisfecissemus in hac parte vestris petitionibus si in illo thesauro coelesti, forsitan ut credebatis, sacris divitiis abundaremus. Nam retroactis temporibus illius thesauri desiderabatur pars maxima, imo fuit totus sub barbarorum persecutione Dei judicio qui habenti tribuit ut abundet non habenti aufert etiam quod videtur habere, proh dolor, incolarum peccatis exigentibus etiam a nostra ecclesia quod sine lachrymis referre non possumus, asportatus solo penes nos ejusdem capite et uno brachio in hoc nobis divina misericordia permittente, remanente. Ipsum etiam a nobis ablatum /fol. 141/ per patrocinii sui gratiam flere non possumus qui et potestates a suis repellit aereas alter Josue et in paucis triumphans de multitudine inimicorum suis adversantium, suis nos tutatur internis externisque meritis, athleta pro suis fortissimus et gloriossimus debellator nec vos ejus carere parte dolore potestis aliqua, qui ut gloriossimus imperator mortis et animas liberat a morte et internis passionibus et externis tuetur peccatis inter vos ejus meritis, Deo antiqua signa innovante, et mirabilia immutante. Justis autem vestris petitionibus voluntario et gratuito concurrentes assensu quousque potuimus, etiam præfatis viris venerabilibus Nicolao decano vestro, Mauritio et Johanne Britone ${ }^{\text {(d) }}$ nomine vestro ad instanter postulantibus et recipientibus amicitiam, confraternitatem, 
consocietatem contraximus. Vos capitulum ecclesiæ (e) beatæ Mariæ Vernonis, omnes videlicet canonicos qui in præsentiarum ecclesia prefata degitis omnesque qui in eadem ecclesia in perpetuum pro tempore sunt futuri, canonicos recipimus in /fol. $141 \mathrm{v}^{\circ}$ / canonicos nostræ ecclesie et in fratres auctoritate Dei et beatae Mariae et gloriossimi patroni nostri beati Maximi, vos omnes universos ac singulos ut dictum est ad beneficia spiritualia et temporalia admittentes et recipientes, si forte contigerit aliquem seu aliquos de vobis præsentibus vel futuris ad ecclesiam nostram videlicet Regensem accedere, ecclesia nostra ipsi vel ipsis in ecclesia, in capitulo et in mensa seu in provisione quotidiana et in praebenda sicut canonico ${ }^{(f)}$ Regiensi per omnia et in omnibus teneatur.

Nos vero juxta Evangelii sententiam dicentis «quaecumque volueritis ut faciant vobis homines et vos facire eis ${ }^{(\mathrm{g})}$, supplicantes exoramus humiliter et quanta possumus devotione pro Deo et beata Dei genitrice et gloriosissimo confessore patrono Maximo ${ }^{(h)}$ ut amicitiam, fraternitatem et societatem mutuam quod sub eadem forma venerabiles viri Nicolaus decanus vester, Mauritius et Joannes Brito pro benignitate vestra et sua nos vestro receperunt nomine, habentes firmam, ratam et inviolabilem per intrumentum vestrum nobis missum /fol. 142/ vestri sigilli roboratum munimine confirmetis. In cujus confœderationis, amicitiæ, fraternitatis et societatis robur et firmitatem indissolubilem pignus gloriosissimum et testimonium inter nos et vos perpetuum per supradictos viros venerabiles legatos vestros vobis destinamus, in insigne charitatis et benevolentiae argumentum, portionem scilicet vestimenti beati Maximi et brachii minus ossulum gloriosae virginis, signis famosæ et miraculis et martyris apostolicæ discipulæ apostoli Pauli Theclæ et contemporaneæ, de reliquiarum corporis ejus thesauri pretiosissimi parte aliqua qua ecclesiam nostram misericordia divina ditavit ut divina pietas petitionum vestrarum effectum multiplicatis intercessoribus largiatur. Remittentes vobis ex affectu charitatis omnem reatum, omnem injuriam et labem peccati si quilibet aut vos aut antecessores vestri incurristis de ablatis dulcissimi confessoris Maximi reliquiis quas habetis, quas constat fuisse de nostra ecclesia Regiensi scilicet asportatas.

Datum apud Regium /fol. $142 \mathrm{v}^{\circ}$ / anno Dominicæ Incarnationis millesimo ducentesimo trigesimo secundo, nono idus maii ${ }^{(j)}$, Gregorio nono sedi apostolicae praesidente anno pontificatus ejus septimo ${ }^{(k)}$, imperante Frederico secundo imperatore Romanorum, Ludovico Francorum rege(l), Ricardo Ebroicensem ecclesiam fœliciter gubernante, Rostagno de Sabrano Regensi episcopo.

(a) Citation de Cicéron, De amicitia, 65 [CICÉRON, Laelius de amicitia, éd. R. COMBÈs, Paris, 1975, p. 41].

(b) Réminiscence de Da 3, 55 et Sg 1,6.

(c) Théroude : vobis nobisque indissolubili charitatis. Vide. Contrahendo.

(d) Sur Nicolas doyen, voir texte a) supra ; Maurice est peut-être le prêtre Maurice de Rouen qui semble entourer le doyen de la collégiale en 1216 et 1227 [L. DELISLE, Cartulaire normand de Philippe Auguste, $\mathrm{n}^{\circ} 198$ et 278], en outre un Mauritius est chanoine d'Évreux au début des années 1230 [V. TABBAGH, Fasti Ecclesice Gallicanæe, t. 20 (Diocèse d'Évreux), Turnhout, 2020, EV427] ; un Jean Brito prêtre paraît comme témoin en 1242 [L. DELISLE, Cartulaire normand..., ibid., $\mathrm{n}^{\circ} 415$ ].

(e) PARIS, BnF, lat. 11066 : ecclesice omis.

(f) PARIS, BnF, lat. 11066 : capitulo.

(g) Mt 7, 12.

(h) PARIS, BnF, lat. 11066 : gloriosissimo confessore nostro Maximo.

(j) Quantième erroné, soit octavo idus maii, soit nono mensis maii.

(k) Calcul erroné, la septième année du pontificat tombe en 1233 pour le mois de mai.

(l) Le décompte à partir des deux règnes semble insolite, à moins de supposer une rédaction conjointe de la lettre par les deux chapitres. 
Tab. 4 - Les dédicaces d'églises à saint Maxime de Riez en Provence centrale (cf. fig. 2).

\begin{tabular}{|c|c|c|c|c|}
\hline Diocèse & $\begin{array}{l}\text { Première } \\
\text { occurrence }\end{array}$ & Localité actuelle & Statut & Source \\
\hline \multirow{8}{*}{ Riez (04) } & 909 & Valensole (04) & prieuré de Cluny & CAC, $\mathrm{n}^{\circ} 105-106$ \\
\hline & 1056 & $\begin{array}{l}\text { Saint-Maimes } \\
\text { (Trigance, 83) }\end{array}$ & $\begin{array}{l}\text { prieuré de Saint-Victor } \\
\text { puis église du Temple de } \\
\text { Rue }\end{array}$ & $\operatorname{CSV}, \mathrm{n}^{\circ} 622$ \\
\hline & 1114 & Riez & cathédrale & GCNN, t. 1 , col. 372 \\
\hline & 1135 & Tavernes (83) & $\begin{array}{l}\text { église de Sainte-Marie de } \\
\text { Barjols (83) }\end{array}$ & WIERDERHOLD, $\mathrm{n}^{\circ} 17$ \\
\hline & 1255 & Sorps (Bauduen, 83) & collégiale & BARTEL, p. 213-219 \\
\hline & 1344 & $\begin{array}{l}\text { Saint-Maime, La } \\
\text { Roquette } \\
\text { (Montmeyan, 83) }\end{array}$ & $\begin{array}{l}\text { locus, toponyme et } \\
\text { «cementerio Sancti } \\
\text { Maximi» }\end{array}$ & AD13, 56 H 4717 \\
\hline & \multirow{2}{*}{$\begin{array}{l}\text { époque } \\
\text { moderne }\end{array}$} & Le Poil $(\text { Senez, } 04)^{(a)}$ & toponyme, Saint-Maïme & $\begin{array}{l}\text { cadastre } 1811 \text {, } \\
\text { feuille A, section } \\
\text { Moulières }\end{array}$ \\
\hline & & $\begin{array}{l}\text { Cornet puis } \\
\text { Châteauredon (04) }\end{array}$ & église paroissiale & \\
\hline \multirow{2}{*}{$\begin{array}{l}\text { Sisteron } \\
\text { (04) }\end{array}$} & ca 1018-1032 & Saint-Maime (04) & Anthroponyme ${ }^{\text {(c) }}$ & CSV,$n^{\circ} 666$ \\
\hline & ca 1168 & Manosque (04) (d) & $\begin{array}{l}\text { église de l'Hôpital, subtus } \\
\text { castrum }\end{array}$ & AD13, 56 H 4627 \\
\hline \multirow[b]{2}{*}{ Gap (05) } & & Venterol & $\begin{array}{l}\text { église paroissiale d'Urtis } \\
(05)\end{array}$ & \multirow[b]{2}{*}{ Manteyer ${ }^{(e)}$} \\
\hline & $\mathrm{XVI}^{\mathrm{e}} \mathrm{s}$. & Ventavon (05) & Chapelle & \\
\hline
\end{tabular}




\begin{tabular}{|l|l|l|l|}
\cline { 2 - 2 } & $\begin{array}{l}\text { Le Villard } \\
\text { Beaume, 05) }\end{array}$ & (La & chapelle \\
\hline
\end{tabular}

(a) Digne-les-Bains, Archives départementales des Alpes-de-Haute-Provence, 105 Fi 153. Le Poil, aujourd'hui rattaché à la commune de Senez : Saint-Maïme, auprès du vallon de Coquas, au nord-est du village du Poil.

(b) Le castrum de Corneto est attesté dès c. 1251, cf. É. BARATIER (éd.), Enquêtes sur les droits et revenus de Charles ler d'Anjou en Provence (1252 et 1278), Paris, 1969, n 523. Avant 1332, il prend le nom de Châteauredon, cf. T. pécout (dir.), L'enquête générale de Leopardo da Foligno dans la baillie de Digne (septembre-octobre 1332), Paris, 2012, p. 157.

(c) Le toponyme et vraisemblablement l'église apparaissent alors sous la forme de l'anthroponyme d'un témoin, Aldebert de Sancto Maximo, à l'occasion de la donation effectuée par le comte Bertrand d'un manse situé dans le castrum de Forcalquier. Vers 1060-1064, le territoire de Sancti Maximi vel Forcalquerii est directement attesté puis en 1126 (Cartulaire de l'abbaye de Saint-Victor de Marseille, éd. B. GUÉRARD, Paris, 1857, n 660 ; J.-P. Poly, La Provence et la société féodale (879-1766), contribution à l'étude des structures dites féodales dans le Midi, Paris, 1976, p. 324). En 1155, l'église Saint-Maxime aurait dépendu du chapitre Saint-Mary de Forcalquier (N. DIDIER, Les églises de Sisteron et de Forcalquier du xi siècle à la Révolution, Paris, 1954, Pièces justificatives, nº 3), mais dès les années 1120-1130 Saint-Maxime à Saint-Maime et Saint-Pierre à Montfuron relèvent de San Giusto de Suse, voir P. L. PATRIA, « II monastero benedettino di San Giusto di Susa, le sue dipendenze e i suoi rapporti con la società oltralpina (Savoie, Provence) », in F. ARneodo et P. guglielmotti (éd.), Attraverso le Alpi : San Michele, Novalesa, san Teofredo e altre reti monastiche, Bari, 2008, p. 115-147, ici p. 123-125. H. Bouche (La chorographie ou description de Provence et l'histoire chronologique du même pays, t. 1, Aix, 1664, p. 239) n'évoque au diocèse de Sisteron que cette dédicace.

(d) L'église est située « subtus castrum » en 1262 dans un acte de l'évêque de Sisteron Alain de Luzarches : LYon, BM, ms. 490, fol. 152-153; J. columBı, De rebus gestis episcoporum Sistaricensium libri quatuor, in J. columBı, Opuscula varia, Lyon, 1668, p. 145-146.

(e) Inventaire dressé par G. de Manteyer ["Les origines chrétiennes de la Deuxième Narbonnaise, des Alpes-Maritimes et de la Viennoise (364-483) », Bulletin de la Société d'études historiques, scientifiques et littéraires des Hautes-Alpes, 5e sér., 43 (1924), p. 316, 322 et 411-412 (n. 166)] à partir notamment de visites épiscopales conservées aux Archives départementales des Hautes-Alpes (1551 et 1582 jusqu'à 1788).

\section{h. Notices martyrologiques et livres liturgiques}

\section{h-1. Martyrologe lyonnais, antérieur à 806}

Au 27 novembre, éloge emprunté à la Vita de Dynamius et rappelant les miracles de Maxime dont trois résurrections de son vivant.

In Galliis civitate Regensi, natale Sancti Maximi episcopi qui a primaeva æata virtutum omnium gratia prædictus, primum Lirinensis cœnobii pater, deinde Regensis ecclesiæ episcopus signis et prodigiis inclytus extitit. Denique inter alia gesta magnifica tres mortuos vivens, unum tactu quo ad sepulchrum vehebatur loculi mortuus suscitavit.

Éd. : H. QUENTIN, Les martyrologes historiques du Moyen Âge. Étude sur la formation du martyrologe romain, Paris, 1908, p. 181-182. J. DUBOIS et G. RENAUD, Édition pratique des martyrologes de Bède, de l'Anonyme lyonnais et de Florus, Paris, 1976, p. 215.

\section{h-2. Martyrologe de Florus, première recension peu avant 837 , seconde recension peu après 837}

Éd. : J. DUBOIS et G. RENAUD, Édition pratique..., ibid., p. 215.

Notice identique au martyrologe lyonnais. 


\section{h-3. Martyrologe d'Adon, vers 855}

Maxime est mentionné au 27 novembre. Notice empruntée à l'Anonyme lyonnais et à Florus.

Éd. : H. QUENTIN, Les martyrologes historiques..., ibid., p. 483. J. DUBOIS et G. RENAUD, Le martyrologe d'Adon. Ses deux familles, ses trois recensions. Texte et commentaire, Paris, 1984, p. 398-399.

\section{h-4. Martyrologe d'Usuard, composé vers 870}

In Galliis civitate Regensi, sancti Maximi confessoris qui a primaeva aetate virtutum omnium gratia praeditus, primum Lirinensis coenobii pater, deinde Regensis ecclesiae episcopus signis et prodigiis inclitus extitit.

Éd. : J. DuBoIs, Le martyrologe d'Usuard. Texte et commentaire, Bruxelles, 1965, p. 349.

\section{h-5. Missel en usage en l'église de Puimoisson}

Missel romain du $\mathrm{Xv}^{\mathrm{e}}$ siècle, en usage en l'église de Puimoisson, provenant d'un couvent des ermites de saint Augustin proche du diocèse de Riez. Formulaire de la messe de la Saint-Maxime en addition $\mathrm{du} \mathrm{Xv}^{\mathrm{e}}$ siècle.

PARIS, BnF, lat. 849 .

Ind. : V. LEROQUAIS, Les sacramentaires et les missels manuscrits des bibliothèques publiques de France, t. 3, Mâcon, 1924, nº 590, p. 34-35 ; J.-L. LEMAITRE, Répertoire des documents nécrologiques français. Supplément, Paris, 1987, $\mathrm{n}^{\circ}$ 3166bis, p. 129.

fol. $231 \mathrm{v}^{\mathrm{o}}$ : In [die] sancti Maximi Regensis episcopi officium. Plebs jocundetur Regensis jure tenetur Maximus hinc cursum complevit ad actum sursum gaudent angelici Christi celus et invicim. Versetus. Cantate Domino canticum novum [Ps 95, 1]. Oratio. Suplicationibus servorum tuorum auctor omnium deus miserator adesto ut quibus beatum Maximum pontificem dedisti patronum respectu gratie tue roborati eum apud te senciant precatorem. Per. Epistola. Ecce sacerdos magnus qui in diebus suis [Si 44, 16]. Responsorium. Maximus hic regis summi renovatio legis atque lucerna gregis fidei munimen et egis. Versetus. Tanto sufulta pastore Regensis adulta tu regio culta nimis hujus honore fulta. Alleluia. Versetus. O flos formose gregis o pastor preciose flagrat more rose tua laus pie vir generose funde preces Domino pro nobis Maxime tino. Evangelium. Sint lumbi vestri precincti [LC 12, 35]. Offertorium. Gemma sacer nomem confessor et inclite totum te sacrificasti Domino vitam reparasti defunctis lumen cecis surdisque cacumen suscipe nos mortis hora cursus rege[.]. Secreta. Oratio. Munera Domine sancti Maximi confessoris tui atque pontificis tibi oblata sufica in emundatione corporis animeque offerentium transfer atque ardencium. Per. Comunio. Christum sumentes pater et tua festa colentes tecum gaudentes facias ipsumque fruentes. Post comunionem. Sacramentis refecti vita libet quesumus deus noster ut beati Maximi confessoris tui atque pontificis fulti juvaminibus pabulo celesti intius sciemur. Per. In [die] sancte Tecle oratio. Sancte martiris ac virginis tue Tecle merita recolentes quesumus Domine miseratus attende ut qui de vite nostre calitate diffidimus ejus meritis et intercessionibus muniri tua gratia interveniente sine fine letemur. Per. Secreta. Sacrificium tibi Domine oblatum intercessione beatissime martiris tue Tecle sume benignus quo a cunctis piaculis expiati que sunt cestia capiamus. Per. Post comunionem. Sumpta sacramenta quesumus Domine populum tuum ad effectum eterne vite deducant sancte Tecle suffragantibus meritis quatenus vitando cadum precipiamus sine fine miri sint. Per. 
Tab. 5 - Les mentions du culte de Maxime de Riez (27 novembre) dans les livres liturgiques provençaux ${ }^{59}$.

\begin{tabular}{|c|c|c|c|}
\hline Type de recueil & Datation & Localisation de la mention & Références \\
\hline \multicolumn{4}{|l|}{ PROVINCE D'AIX } \\
\hline $\begin{array}{l}\text { Sacramentaire d'Apt } \\
\text { [APT, Trésor, ms. 11] }\end{array}$ & $\mathrm{XII}^{\mathrm{e}} \mathrm{s}$. & litanies & $\mathrm{I}, 1, \mathrm{n}^{\circ} 119$ \\
\hline $\begin{array}{l}\text { Psautier d'Apt [APT, Trésor, } \\
\text { ms. 9] }\end{array}$ & fin du XIII ${ }^{\mathrm{e}} \mathrm{s}$. & calendrier : Maximi et Siffredi & II, $1, \mathrm{n}^{\circ} 21$ \\
\hline $\begin{array}{l}\text { Bréviaire d'Aix [MARSEILLE, } \\
A D \text { 13,2 G 1859] }\end{array}$ & XIV $\mathrm{s}$ & $\begin{array}{l}\text { calendrier: Maximi Regensis ep. et conf. } \\
\text { IX lect. } \\
\text { litanies, fol. } 71 \\
\text { sanctoral, fol. } 305 v^{\circ}-306 \text { : Sancti Maximi. } \\
\text { Oratio Supplicationibus servorum tuorum } \\
\text { [...] te sentiant preccatorem. Per. Lectio I } \\
\text { Beatissimi Maximi Regenis urbis [...] Lectio } \\
\text { VI [...] christianis parentibus editus factus } \\
\text { illico christianus. Evangelium Sint lumbi } \\
\text { vestri. Quare in comuni confessorum. }\end{array}$ & $\begin{array}{l}\text { III, } 2, \\
n^{\circ} 335\end{array}$ \\
\hline $\begin{array}{l}\text { Diurnal de Fréjus [PARIS, BnF, } \\
\text { lat. 1068] }\end{array}$ & $\begin{array}{l}\mathrm{XIV}^{\mathrm{e}} \text { s., après } \\
1323\end{array}$ & $\begin{array}{l}\text { calendrier: Maximi ep. et confol. } \\
\text { sanctoral, fol. } 82 \mathrm{v}^{\mathrm{o}} \text { : In festo sancti } \\
\text { Maximi episcopi et conf. oratio. } \\
\text { Supplicationibus servorum tuorum [...] te } \\
\text { sentiant precatorem. Per Dominum } \\
\text { nostrum. } \\
\text { litanies }\end{array}$ & \\
\hline $\begin{array}{l}\text { Missel romain utilisé par un } \\
\text { évêque de Riez [PARIS, BnF, } \\
\text { lat. 828] }\end{array}$ & $1342-1352$ & calendrier : sancti Maximi ep. et conf. & I, $2, n^{\circ} 465$ \\
\hline $\begin{array}{l}\text { Bréviaire de Fréjus [PARIS, BnF, } \\
\text { lat. 1261] }\end{array}$ & $x v^{e} s$ & sanctoral, fol. 434 : Sancti Maximi ep. & $\begin{array}{l}\text { III, } 3, \\
n^{\circ} 533\end{array}$ \\
\hline $\begin{array}{l}\text { Bréviaire d'Aix [PARIS, BnF, } \\
\text { lat. 1061] }\end{array}$ & 1467 & $\begin{array}{l}\text { litanies } \\
\text { sanctoral, fol. } 368 \mathrm{v}^{\circ} \text { : In festo sancti } \\
\text { Maximi ep. et conf. }\end{array}$ & $\begin{array}{l}\text { III, } 3, \\
n^{\circ} 520\end{array}$ \\
\hline
\end{tabular}




\begin{tabular}{|c|c|c|c|}
\hline $\begin{array}{l}\text { Bréviaire de Riez [DRAGUIGNAN, } \\
\text { BM, ms. } 3 \text { (R6)] }\end{array}$ & $x^{e} s$. & $\begin{array}{l}\text { hymnaire, fol. } 13 \mathrm{v}^{\circ}: \text { In festo sancti } \\
\text { Maximi hymnus; fol. } 14 \text { hymnus } \\
\text { collectaire, fol. } 26 \mathrm{v}^{\circ} \text { : Sancti Maximi ep. } \\
\text { et conf. } \\
\text { sanctoral, fol. } 132 \mathrm{v}^{\circ}-134 \text { : Beati Maximi } \\
\text { Regensis ep. et conf. Lectio prima } \\
\text { Beatissimi Maximi Regensis urbis antistitis } \\
\text { hodie dies solempnitatis excolitur [...] } \\
\text { Lectio IX [...] evanuit inter hec navis fictilis } \\
\text { ab oculis exorantis. }\end{array}$ & $\begin{array}{l}\text { III, } 2, \\
n^{\circ} 254\end{array}$ \\
\hline $\begin{array}{l}\text { Psautier de Beauvais, en } \\
\text { usage chez les frères Mineurs } \\
\text { de Riez en } 1484 \text { [NEW YoRK, } \\
\text { Pierpont Morgan Library, } \\
\text { MS 101] }\end{array}$ & ca $1275-1300$ & $\begin{array}{l}\text { calendrier, add. } \mathrm{xV}^{\mathrm{e}} \mathrm{s} . \text { : Maximi episcopi } \\
\text { et confessoris Regensis }\end{array}$ & (a) \\
\hline \multicolumn{4}{|l|}{ PROVINCE D'EMBRUN } \\
\hline $\begin{array}{l}\text { Bréviaire de } \quad \begin{array}{c}\text { Senez } \\
\text { [CARPENTRAS, } \\
\text { Inguimbertine, }\end{array} \text { ms. 72] }\end{array}$ & $\begin{array}{l}\text { fin } \quad \mathrm{XII}^{\mathrm{e}} \text { s.- } \\
\text { déb. } \mathrm{XIII}^{\mathrm{e}} \mathrm{s} \text {. }\end{array}$ & $\begin{array}{l}\text { calendrier: |Maximi ep. IX lect./ au } \\
\text { 25/06; Maximi Regensis ep. VIIII lect. }\end{array}$ & $\begin{array}{l}\text { III, } 1, \\
n^{\circ} 144\end{array}$ \\
\hline $\begin{array}{l}\text { Sacramentaire de Digne } \\
\text { [DIGNE, BM, ms. 1] }\end{array}$ & $\begin{array}{l}\text { fin } \quad \text { XIII }{ }^{\mathrm{e}} \text { s.- } \\
\text { déb. } \mathrm{XIV}^{\mathrm{e}} \mathrm{s} .\end{array}$ & $\begin{array}{l}\text { fol. } 142 \mathrm{v}^{0}-143, \quad \text { trois } \text { oraisons } \mathrm{du} \\
\text { propre : Sancti Maximi }\end{array}$ & (b) \\
\hline $\begin{array}{l}\text { Bréviaire, couvent OESA } \\
\text { [Castellane ?] }\end{array}$ & début $\mathrm{XIV}^{\mathrm{e}} \mathrm{s}$. & $\begin{array}{l}\text { sanctoral, fol. } 343 \text { : In festo sancti Maximi } \\
\text { ep., tiré du commun }\end{array}$ & $\begin{array}{l}\text { III, } 3, \\
n^{\circ} 558\end{array}$ \\
\hline $\begin{array}{l}\text { Missel de Digne [MARSEILLE, } \\
B M V R, \text { ms. 104] }\end{array}$ & XIV $\mathrm{s}$. & $\begin{array}{l}\text { sanctoral, fol. } 249 \text {, trois oraisons et } \\
\text { leçons de l'office pour les deux saints : } \\
\text { Maximi et Cifredi }\end{array}$ & I, $2, \mathrm{n}^{\circ} 461$ \\
\hline $\begin{array}{l}\text { Missel romain, couvent OESA } \\
\text { [PARIS, BnF, lat. 849] }\end{array}$ & XIV $\mathrm{s}$. & $\begin{array}{l}\text { calendrier: MMaximi ep. et conf. IIII } \\
\text { capas/ } \\
\text { add., fol. } 231 \mathrm{v}^{\circ}: \text { In sancti Maximi ep.; } \\
\text { add. fol. } 232 \text {, trois oraisons : Missa beati } \\
\text { Maximi }\end{array}$ & $\begin{array}{l}\text { I, } 3 \\
n^{\circ} 590^{\text {(c) }}\end{array}$ \\
\hline $\begin{array}{l}\text { Missel de Grasse [GRASSE, BM, } \\
\text { ms. } 3 \text { (192-R2)] }\end{array}$ & ca 1316-1334 & calendrier : Maximi ep. et conf. & $\begin{array}{l}\text { I, } 2 \\
n^{\circ} 386 \text { (d) }\end{array}$ \\
\hline $\begin{array}{l}\text { Bréviaire de Vence et Grasse } \\
\text { [CARPENTRAS, Bibliothèque } \\
\text { Inguimbertine, ms. 42] }\end{array}$ & ca 1323-1363 & calendrier de Vence : Maximi ep. et conf. & $\begin{array}{l}\text { III, } 1, \\
n^{\circ} 135\end{array}$ \\
\hline
\end{tabular}




\begin{tabular}{|c|c|c|c|}
\hline $\begin{array}{l}\text { Lectionnaire de l'office de } \\
\text { Digne [AVIGNON, Médiathèque } \\
\text { Ceccano, ms. 219] }\end{array}$ & ca $1340-1370$ & $\begin{array}{l}\text { fol. } 242 \mathrm{v}^{\circ}-244 \mathrm{v}^{\circ} \text {, neuf leçons : In festo } \\
\text { sancti Maximi Regensis episcopi. Lectio I. } \\
\text { Beatissimi Maximi Regensis urbis antistitis } \\
\text { [...] Lectio IX. [...] equitas singularem } \\
\text { humilitas pauperem dignitas afluentem. Tu } \\
\text { autem. }\end{array}$ & (e) \\
\hline $\begin{array}{l}\text { Bréviaire de Lérins [PARIS, } \\
\text { BnF, lat. 10486] }\end{array}$ & $\begin{array}{l}\text { dernier } \\
\text { quart du } \\
\mathrm{XV}^{\mathrm{e}} \mathrm{s} .\end{array}$ & $\begin{array}{l}\text { calendrier : Maximi ep. lect. XII duplex } \\
\text { sanctoral, hymne et oraisons du } \\
\text { propre, fol. } 518-518 \mathrm{v}^{\mathrm{o}} \text { : Maximi ep. } \\
\text { Hymnus. Vir excelsi meritis athleta Christi } \\
\text { Maxime quas devote effundimus tu preces } \\
\text { nostras suscipe [...] ejus filium et utriusque } \\
\text { spiritum ardamus omni tempore. Amen. }\end{array}$ & $\begin{array}{l}\text { III, } 3, \\
n^{\circ} 601\end{array}$ \\
\hline $\begin{array}{l}\text { Bréviaire de Digne [PARIS, BnF, } \\
\text { nouv. acq. lat. 1113] }\end{array}$ & $1494-1496$ & $\begin{array}{l}\text { sanctoral, fol. } 216 \text { : Sancti Maximi ep. } \\
\text { Regensis }\end{array}$ & $\begin{array}{l}\text { III, } \quad 3, \\
n^{\circ} 678\end{array}$ \\
\hline \multicolumn{4}{|l|}{ PROVINCE D'ARLES } \\
\hline $\begin{array}{l}\text { Sacramentaire d'Apt } \quad \text { [APT, } \\
\text { Trésor, ms. 10] }\end{array}$ & fin $\mathrm{XII}^{\mathrm{e}} \mathrm{s}$. & $\begin{array}{l}\text { calendrier d'Avignon, fol. } 107 \text { : Maximi } \\
\text { atque Sifredis commemoratio }\end{array}$ & $\mathrm{I}, 1, \mathrm{n}^{\circ} 118$ \\
\hline $\begin{array}{l}\text { Sacramentaire de Caromb } \\
\text { (diocèse de Carpentras) } \\
\text { [AVIGNON, Médiathèque Ceccano, } \\
\text { ms. 143] }\end{array}$ & fin $\mathrm{XIII}^{\mathrm{e}} \mathrm{s}$. & calendrier : Maximi ep. et conf. & I, $2, n^{\circ} 345$ \\
\hline $\begin{array}{l}\text { Psautier de Paris et de Saint- } \\
\text { Césaire d'Arles [BORDEAUX, BM, } \\
\text { ms. 7] }\end{array}$ & $\begin{array}{l}2^{\mathrm{e}} \text { moitié du } \\
\mathrm{XIII}^{\mathrm{e}} \mathrm{s}\end{array}$ & $\begin{array}{l}\text { calendrier, fol. } 5 \mathrm{v}^{\circ} \text { en add.: Maximi, } \\
\text { Siffredi ep. et conf. }\end{array}$ & II, $1, \mathrm{n}^{\circ} 74$ \\
\hline $\begin{array}{l}\text { Missel de Saint-Trophime } \\
\text { d'Arles [PARIS, BnF, lat. 875] }\end{array}$ & début XIV s. & $\begin{array}{l}\text { sanctoral, fol. } 218 \text {, oraisons du propre : } \\
\text { In festo sancti Maximi }\end{array}$ & I, $2, \mathrm{n}^{\circ} 376$ \\
\hline $\begin{array}{l}\text { Bréviaire de Carpentras } \\
\text { [CARPENTRAS, } \\
\text { Inguibliothèque }\end{array}$ & $\mathrm{XIV}^{\mathrm{e}} \mathrm{s}$ & $\begin{array}{l}\text { calendrier: Sancti Syffredi ep. et conf. IX } \\
\text { lectiones et Maximi ep. }\end{array}$ & $\begin{array}{l}\text { III, } \quad 1, \\
n^{\circ} 146\end{array}$ \\
\hline $\begin{array}{l}\text { Missel de Saint-Victor de } \\
\text { Marseille } \\
\text { Bibliothèque IngRPENTRAS, } \\
\text { ms. } 90 \text { (L106)] }\end{array}$ & $\begin{array}{l}1^{\text {re }} \text { moitié du } \\
\text { XIV }^{\mathrm{e}} \mathrm{s} .\end{array}$ & $\begin{array}{l}\text { calendrier : Maximi ep. et conf. } \\
\text { sanctoral, fol. } 281-281 \mathrm{v}^{\circ} \text {, trois oraisons } \\
\text { du propre : Sancti Maximi conf. officium. }\end{array}$ & I, $2, \mathrm{n}^{\circ} 456$ \\
\hline $\begin{array}{l}\text { Bréviaire de Saint-André de } \\
\text { Villeneuve [BESANçON, BM, } \\
\text { ms. 137] }\end{array}$ & $\begin{array}{l}2^{\mathrm{e}} \text { moitié du } \\
\mathrm{xV}^{\mathrm{e}} \mathrm{s} .\end{array}$ & calendrier : Maximi ep. et conf. & III, $1, \mathrm{n}^{\circ} 93$ \\
\hline $\begin{array}{lrr}\text { Bréviaire } & \text { romain } & \text { et } \\
\text { avignonnais } & \text { [LYON, } & \text { BM, } \\
\text { ms. } 550(468)] & & \end{array}$ & $x v^{e} s$ & calendrier : Maximi ep. et conf. & $\begin{array}{l}\text { III, 2, } \\
n^{\circ} 315\end{array}$ \\
\hline
\end{tabular}




\begin{tabular}{|c|c|c|c|}
\hline $\begin{array}{l}\text { Missel d'Arles [CARPENTRAS, } \\
\text { Bibliothèque Inguimbertine, } \\
\text { ms. } 87 \text { (L102)] }\end{array}$ & $x v^{e} s$ & $\begin{array}{l}\text { sanctoral, fol. } 208 \mathrm{v}^{\circ} \text {, une oraison: In } \\
\text { festo sancti Maximi }\end{array}$ & I, 3, n $\mathrm{n}^{\circ} 654$ \\
\hline $\begin{array}{l}\text { Bréviaire de Marseille [PARIS, } \\
B n F \text {, lat. 1060] }\end{array}$ & $\mathrm{XV}^{\mathrm{e}} \mathrm{s}$ & litanies, fol. 96 $\mathrm{v}^{\circ}$ & $\begin{array}{l}\text { III, 3, } \\
\text { n } 519\end{array}$ \\
\hline
\end{tabular}

(a) R. BRANnER, «The Johannes Grusch Atelier and the Continental Origins of the William of Devon Painter », The Art Bulletin, 54/1 (1972), p. 24-30. M. R. JAmEs, Catalogue of Manuscripts and early printed Books from the Libraries of William Morris, Richard Bennett, Bertram fourth Earl of Ashburnham, and other Sources. Manuscripts, Londres, 1906, n²0, p. 43-46. A. stonEs, « Les manuscrits du cardinal Jean Cholet et l'enluminure beauvaisienne vers la fin du xIII siècle ", in L'art gothique dans l'Oise et ses environs : architecture civile et religieuse, peinture murale, sculpture et arts précieux, etc., s. I., 2001, p. 239-266, ici p. 263-266, fig. 490-497. A. stones, Gothic Manuscripts (1260-1320), Londres, 2013-2014, t. I-7, p. 53-55, fig. 74-77 ; t. I-2, p. 15, 33-36 ; t. II-2, p. 215, 224.

(b) T. PÉcout, «Le sacramentaire du chapitre cathédral de Digne (Digne, Bibl. municipale, ms 1) », Provence historique, 70 (2020), p. 287-293.

(c) J.-L. Lemaitre, Répertoire des documents nécrologiques français, Paris, 1980-1992, nº 3166bis.

(d) Catalogue des manuscrits en écriture latine portant des indications de date, de lieu ou de copiste, t. 6 (Bourgogne, Centre, Sud-Est et Sud-Ouest de la France), éd. C. samaran et R. marichal, Paris, 1968, p. 215, pl. XLII. M. weIBEL, Liturgie des saints et confréries laïques au Moyen Âge. À propos du sanctoral de la confrérie de "l'Aumône de la Miséricorde » de Nice et de la confrérie Saint-Jacques de Narbonne, master professionnel, Sciences de l'information et des bibliothèques, université de Lyon II, 2016 (dactylographié).

(e) T. PÉCOUt, « Le culte de Marcellin d'Embrun », à paraître.

\section{i. Hymnes et antiennes à Maxime de Riez}

- Hymne Ad vesperas et nocturnum, «O vir excelse meritis [...] ardamus omni tempore ». Il est présent dans les Bréviaires de Riez [XV siècle, DRAGUIGNAN, BM, ms. 3 (R6), fol. 13v $\mathrm{v}^{\mathrm{o}}-14$ ], de Lérins [ $\left[\mathrm{XV}^{\mathrm{e}}\right.$ siècle, PARIS, BnF, lat. 10486], d'un couvent OESA [XIV ${ }^{\mathrm{e}}$ siècle, PARIS, BnF, lat. 1285], d'Aix (Lyon, 1499), les offices propres de Riez de 1635 et de $1675^{60}$.

Éd. : V. BARRALIS, Chronologia sanctorum..., op. cit., p. 129 ; Analecta Hymnica Medii Aevi, t. 11 (Hymni inediti. Liturgische Hymnen des Mittelalters aus Handschriften und Wiegendrucken), $2^{\mathrm{e}}$ série, éd. C. BLUME et G. M. DREVES, Leipzig, 1891, nº 358, p. 194-195.

Ind. : Repertorium hymnologicum. Catalogue des chants, hymnes, proses, séquences, tropes, en usage dans l'Église latine depuis les origines jusqu'à nos jours, éd. U. CHEVALIER, Louvain, $1892-1920, \mathrm{n}^{\circ} 13886$.

- Hymne Ad laudes, « Stella fulgens matutina [...] Vitce dantur promia ». Il est issu des Bréviaires de Riez [XV ${ }^{\mathrm{e}}$ siècle, DRAGUIGNAN, BM, ms. 3 (R6), fol. 14], de l'abbaye de Lérins [XV siècle, PARIS, BnF, lat. 10486], d'un couvent OESA [XIV siècle, PARIS, BnF, lat. 1285], d'Aix (Lyon, 1499, 1477 et 1526), des offices propres de Riez (1635 et 1675) ${ }^{61}$.

Éd. : V. BARRALIS, Chronologia sanctorum..., op. cit., p. 130 ; Analecta Hymnica..., ibid., n 359 , p. 195.

Ind. : Repertorium hymnologicum, $\mathrm{n}^{\circ} 19441$. 


\section{NOTES}

1. Riez, dép. des Alpes-de-Haute-Provence, ch.-l. canton. J.-J.-M. FÉRAUD, Les saints tutélaires de l'église de Riez ou vies des saints évêques Maxime et Fauste et de sainte Thècle, Digne, 1850, p. 1-41, 105-110 et 119-128.

2. M.-O. GARRIgueS, s. v. "Massimo di Riez», in Bibliotheca sanctorum, t. 9, Rome, 1967, col. 64-65. s. v. « Saint Maxime », in Vies des saints et des bienheureux, t. 11, Paris, 1954, p. 936-939. M. Heijmans, s. v. « Maximus 4 », in L. PIETRI et M. Heijmans (éd.), Prosopographie chrétienne du BasEmpire, t. 4/2 (La Gaule chrétienne, 314-614), Paris, 2013, p. 1295-1300. P. BOULHOL et P.-A. JACOB, Maxime de Riez entre l'histoire et la légende. Dynamius le Patrice, Vie de saint Maxime, évêque de Riez. Fauste de Riez, Panégyrique de saint Maxime, évêque et abbé, Valensole, 2014, p. 62-74. S. PRIcoco, L'Isola dei Santi. Il cenobio di Lerino e le origini del monachesimo gallico, Rome, 1978. M. FAUQUIER, Martyres pacis. La sainteté en Gaule à la fin de l'Antiquité et au début du Moyen Âge (IV ${ }^{e}-V I^{e}$ siècle), Paris, 2018.

3. Ce siège a probablement été érigé sous le règne de l'empereur Honorius (395-423), de même qu'une série d'autres diocèses du nord de la péninsule italienne. Précocement attesté en comparaison des cités voisines de Sisteron, Senez et Glandèves, signalées seulement au $\mathrm{VI}^{\mathrm{e}}$ siècle, le diocèse de Riez se place néanmoins parmi les créations les plus tardives au regard de la Provence rhodanienne et maritime. R. BUSQUET, «Les évêchés provençaux à l'époque romaine ", Provence historique, 2 (1951), p. 114. J.-M. Roux, «Les évêchés provençaux de la fin de l'époque romaine à l'avènement des Carolingiens (476-751) », Provence historique, 21 (1971), p. 376-377. Maxime est probablement le successeur immédiat de l'abbé Honorat, qui quitte son siège pour la cité d'Arles vers 427-428 selon S. PRICOco, L'Isola dei Santi..., ibid., p. 36 (n. 37) et 43. Il serait demeuré sept années à l'abbatiat de Lérins, selon Fauste (EuSEBIUS GaLLICANUS, Collectio Homiliarum. Sermones extravagantes, éd. F. GLORIÉ, Turnhout, 1970, XXXV, 4, p. 403 ; S. PRICOCO, L'Isola dei Santi..., ibid., p. 48-49). J.-P. POLY, «La "Petite Valence". Les avatars domaniaux de la noblesse romane en Provence", in Saint Mayeul et son temps, Digne, 1997, p. 168-169, n. 1 : l'auteur prête à Maxime deux prédécesseurs : Ours, présent au concile de Turin en 398, et Maurin, mentionné dans la correspondance pontificale en 419 et 431 . Nous n'avons pu consulter à temps un travail inédit: L. RIPART, Pouvoirs, Église et société dans le royaume d'Arles ( $V^{e}-X V^{e}$ siècle), mémoire d'habilitation à diriger les recherches, université Côte d'Azur, 2019 (dactylographié).

4. Dinamii vita sancti Maximi episcopi Reiensis. Fausti Reiensis sermo de sancto Maximo episcopo et abbate, éd. S. GENNARO, Catane, 1966 : Vita sancti Maximi 3, 60, p. 71 : in vico proprio cui vocabulum est de Comeco, vraisemblablement le lieu-dit Cornet (chapelle Notre-Dame de Cornet, com. de Châteauredon, canton de Flayosc). Cette identification semble aller de soi à Riez et figure au propre de 1635 : L. DONI D'ATTICHY, Officia propria sanctorum sanctoe Regiensis Ecclesio, Aix, 1635, p. 5. La leçon Cometo/Comeco (voire Decomeco/Decometo) transmise par les manuscrits de la Vita Maximi est une très plausible erreur pour Corneto. P. BOULHOL et P.-А. ЈАСОВ, Maxime de Riez..., op. cit., p. 61 (n. 91) et 97 (n. 240).

5. Sur ce milieu : W. E. KLINGSHIRN, Coesarius of Arles. The Making of a Christian Community in Late Antique Gaul, Cambridge, 1994. M. HEIJMANS et L. PIETRI, « Le "lobby" lérinien : le rayonnement du monastère insulaire du $\mathrm{v}^{\mathrm{e}}$ siècle au début $\mathrm{du} \mathrm{VII}^{\mathrm{e}}$ siècle ", in Y. CODOU et M. LAUWERS (éd.), Lérins, une île sainte de l'Antiquité au Moyen Âge, Turnhout, 2009, p. 35-61. Sur le monachisme lérinien: H. MORIS, «L'abbaye de Lérins, son histoire, ses possessions, ses monuments anciens ", Annales de la Société des lettres, sciences et arts des Alpes-Maritimes, 19 (1905), p. 299-399 ; 20 (1907), p. 227-373 ; 21 (1909), p. 157-316 et 22 (1909), p. 1-66; H. LECLERCQ, s. v. «Lérins ", in Dictionnaire d'archéologie chrétienne et de liturgie, t. 8, Paris, 1929, col. 2596-2627. Sur la spiritualité lérinienne : R. NOUAILHAT, Saints et patrons. Les premiers moines de Lérins, Besançon, 1988 ; C. M. KASPER, Theologie und Askese. Die Spiritualität des Inselmönchtums von Lérins im 5. Jahrhundert, Aschendorff, 1991. M. LABRousSE, 
"Les origines du monastère ( $\mathrm{v}^{\mathrm{e}}-\mathrm{VII}$ e siècle) ", in M. LABROUSSE et al. (éd.), Histoire de l'abbaye de Lérins, Bellefontaine, 2006, p. 23-124.

6. Le 18 novembre 439. C. J. HEFELE et H. LECLERCQ, Histoire des conciles d'après des documents originaux, trad., t. 2/1, Paris, 1908, p. 423 sqq. Concilia Gallice a. 314-a. 506, éd. C. MUNIER, Turnhout, 1963, p. 61-75. Souscription de Maxime sans mention de siège épiscopal.

7. Respectivement les 8 novembre 441 et 13 novembre 442 : Concilia Gallice a.314..., ibid., p. 87 et 102 .

8. Concilia Gallice a. 314..., ibid., p. 107 et 109.

9. Concilia Gallice a. 314..., ibid., p. 132.

10. S. PRICOCO, L'Isola dei Santi..., op. cit., p.55-56 et n. 122 (voyage de l'évêque Fauste à Rome); Concilia Gallice a. 314..., ibid., p. 159.

11. G. BARRUOL, Les peuples préromains du Sud-Est de la Gaule. Étude de géographie historique, Paris, 1969, p. 219, n. 5. Sur Riez durant l'Antiquité tardive : J.-R. PALANQUE, « Les évêchés provençaux à l'époque romaine», Provence historique, I (1951), p.114, 139. J.-M. Roux, "Les évêchés provençaux... », op. cit., p. 414-415. J. GUYON, « Riez », in Topographie chrétienne des cités de la Gaule, t. 2, Paris, 1990, p. 35-42. Pour une vue d'ensemble, P.-A. FÉVRIER, «La marque de l'Antiquité tardive dans le paysage religieux médiéval de la Provence rurale ", in M. FIXOT et É. ZADORA-RIO (éd.), L'environnement des églises et la topographie religieuse des campagnes médiévales, Paris, 1994, p. 27-35.

12. La pénétration du christianisme dans cette région ne semble pas antérieure au $\mathrm{IV}^{\mathrm{e}}$ siècle : un doute subsiste toutefois, puisqu'une inscription présente sur un cippe du début du IV siècle ou de la fin $\mathrm{du} \mathrm{III}^{\mathrm{e}}$ siècle pourrait concerner un chrétien: A. CHASTAGNOL, Inscriptions latines de Narbonnaise, t. 2, Paris, 1992, $\mathrm{n}^{\circ} 25$.

13. G. BARRUOL, "Riez antique », Annales de Haute Provence, 283-284 (1979) [Riez], p. 14-21. P.A. FÉVRIER, « Riez », in F. BENOIT et al. (éd.), Villes épiscopales de Provence: Aix, Arles, Fréjus, Marseille et Riez, de l'époque gallo-romaine au Moyen Âge, Paris, 1954, p. 39-43. Gallia, t. 25/2 (1967), p. 392-395 et 32/2 (1974), p. 521-522. J. GUYON, «Riez », op. cit., p. 40-41; ID., "L'évolution des sites urbains en Provence (Antiquité et Haut Moyen Âge). L'exemple de Marseille, Aix, Arles et Riez à la lumière des recherches et fouilles récentes ", Ktema, 7 (1982), p.129-140. Sur la reconstruction de la cathédrale à la fin du $\mathrm{x}^{\mathrm{e}}$ siècle : J. CHAMBONNET, «La cathédrale ", Annales de Haute-Provence, 315 (1985) [Alpes-de-Haute-Provence. Les cathédrales, t. 1], p. 201-238. G. BAIHACHE, « Le baptistère de Riez ", in Congrès archéologique de France, 95 session, Aix, 1932, Paris, 1934, p. 75-88. J. FORMIGÈ, "Remarques diverses sur les baptistères de Provence », in Mélanges en hommage à la mémoire de F. Martroye, Paris, 1940, p. 167-190. A. DonNADiEU, «Le baptistère de Riez », Comptes rendus de l'Académie des inscriptions et belles lettres, 1950, p.159-167. J. GUYON, «Baptistères et groupes épiscopaux de Provence. Élaboration, diffusion et devenir d'un type architectural », in Actes du $\mathrm{XI}^{e}$ Congrès international d'archéologie chrétienne, Lyon, Vienne, Grenoble, Genève et Aoste (septembre 1986), t. 2, Rome, 1989, p.1227-1449. G. BARRUOL, «Riez, Groupe épiscopal. Cathédrale et baptistère ", in N. DUVAL (dir.), Les premiers monuments chrétiens de la France, t. 1 (Sud-Est et Corse), Paris, 1995, p. 85-93. J. GUYON, « Les baptistères au ve siècle » in M. ROUCHE (éd.), Clovis, histoire et mémoire. Clovis et son temps, l'événement, Paris, 1997, p. 255-269. La ville antique et tardo-antique est désormais beaucoup mieux connue à l'issue de plusieurs campagnes de fouilles et de la restauration du baptistère : P. BORGARD et C. MICHEL D'ANNOVILLE, «Le groupe épiscopal de Riez », in Albenga città episcopale. Tempi e dinamiche della Cristianizzazione tra Liguria di Ponente e Provenza, Albenga, 2007, p. 839-862. P. BORGARD, « Le baptistère de Riez, de Simon Bartel à Marcel Provence. Heurs et malheurs d'un "Panthéon" converti en musée lapidaire ", in J.-E. BROCHIER, A. GUILCHER et M. PAGNI (éd.), Mélanges offerts à Gaëtan Congès et Gérard Sauzade, Aix-en-Provence, 2008, p. 767-789. P. BORGARD et C. MICHEL D'ANNOVILLE, «Le groupe épiscopal de Riez: insertion et évolution des 
bâtiments au sein de la ville à la fin de l'Antiquité et au haut Moyen-Âge ", in S. GUIZANI (éd.), Urbanisme et architecture en Méditerranée antique et médiévale à travers les sources archéologiques et littéraires, Tunis, 2013, p. 293-306. P. BORGARD, M. HEIJMANS et C. MICHEL D'ANNOVILLE, s. v. « Riez », in F. PRÉVOT, M. GAILLARD et N. GAUTHIER, Topographie chrétienne des cités de la Gaule des origines au milieu du VIII siècle, t. 16/1 (Province ecclésiastique d'Aix. Compléments au t.2), éd. Paris, 2014, p. 35-42. P. BORGARD et C. MICHEL D'ANNOVILLE, «Insertion de la cathédrale dans la ville antique, ses origines, son devenir: l'exemple du groupe épiscopal de Riez (Alpes-de-Haute-Provence) », Provence historique, 65 (2015), p. 79-91. Sur la topographie du Riez médiéval : T. PÉcouT, « La ville de Riez. L'espace urbain à travers les documents écrits. Apports et limites pour les $\mathrm{XI}^{\mathrm{e}}-\mathrm{XV}^{\mathrm{e}}$ siècles ", in P. BORGARD (éd.), Riez une capitale en Haute Provence, de l'Antiquité aux Temps modernes, Actes du colloque international de Digne et Riez, 25-27 septembre 2009, à paraître.

14. Cette église Saint-Pierre est le théâtre des premiers miracles accomplis par Maxime, si l'on en croit la Vita Maximi (BHL 5853) : Dinamii vita sancti Maximi..., op. cit., 1.494, p. 119, et sa version abrégée (BHL 5856) Vita sancti Maximi episcopi reiensis, ibidem, § 20, p. 165. Au siècle suivant, selon Grégoire de Tours (BHL 5855) : MGH, Scriptores rerum merovingicarum, t. 1, In Gloria confessorum, 82, éd. B. KRUSCH, Hanovre, 1885, p. 800-801. M. VIEILLARD-TROIEKOUROFF, Les monuments religieux de la Gaule d'après les œuvres de Grégoire de Tours, Paris, 1976, n² 225, p. 239-240.

15. Originaire de Bretagne, moine à Lérins vers 423-427, Fauste en devient abbé en 434 . Il participe aux débats théologiques entourant la prédestination et l'économie de la grâce déclenchés par le pélagianisme, avant d'affronter l'arianisme, ce qui lui vaut en 478 la disgrâce du roi wisigoth Euric mort en 484. Peut-être présent au concile de Rome en 462 où il représente l'épiscopat du sud de la Gaule auprès du pape Hilaire, ou d'Arles vers 449-461 alors qu'il était abbé de Lérins (Concilia Gallice a.314..., op. cit., p. 132), il l'est assurément comme évêque à celui d'Arles vers 470 (Concilia Gallice a.314..., ibid., p. 154) où sont débattus les problèmes de la prédestination. S. PRICOCo, L'Isola dei Santi. Il cenobio di Lerino e le origini del monachesimo gallico, Rome, 1978, p. 55-56. R. BARCELLONA, «Fausto di Riez, defensor civitatis et defensor orthodoxiae. Sul ruolo del vescovo in Gallia nel v secolo ", in Vescovi e Pastori in epoca teodosiana. In occasione del XVI centenario della consacrazione episcopale di S. Agostino (396-1996), Rome, 1997, p. 777-802. EAD., Fausto di Riez interprete del suo tempo: un vescovo tardoantico dentro la crisi dell'impero, Catanzaro, 2006. M. heijmans et L. PIETRI, "Le "lobby" lérinien... », op. cit., p. 35-61. M. heijMAns, s. v. «Faustus 1 », in Prosopographie chrétienne du Bas-Empire..., op. cit., t.4/1, p.734-744. Sur les interventions de Fauste dans les querelles dogmatiques : Dictionnaire de théologie catholique, Paris, t. 9 (1926), col. 1020-1024; t. 14 (1939), col. 1033-1038 et 2101-2105. Fausti Reiensis Opera praeter sermones pseudoeusebianos, éd. A. ENGELBRECHT, Prague/Vienne/Leipzig, 1891 : De Gratia, p. 3-98 (vers 473) ; De Spiritu Sancto, p. 99-157 ; De Ratione Fidei, p. 451-459 ; Lettres dogmatiques, p. 168-191 et 200-211. G. WEIGEL, Faustus of Riez. An Historical Introduction, Philadelphie, 1938. FAUSTO DI RIEZ, Lo Spirito Sancto, éd. C. MiCAELli, Rome, 1997. S. GIOANNI, " Moines et évêques en Gaule aux ve et $\mathrm{VI}^{\mathrm{e}}$ siècles: la controverse entre Augustin et les moines provençaux ", Médiévales, 38 (2000), p. 149-162. Pour sa correspondance avec Ruricius de Limoges : R. W. MATHISEN, Ruricius of Limoges and Friends. A Collection of Letters from visigothic Gaul, Liverpoll, 1999, p. 237-252. Fauste est sans doute mort dans la dernière décennie $d u v^{e}$ siècle.

16. BHL 5852. Le panégyrique fait partie d'une collection de sermons constituée vers le début du $\mathrm{VI}^{\mathrm{e}}$ siècle dans les milieux entourant Césaire d'Arles et longtemps attribuée à Eusèbe Gallican ou d'Emèse : «Eusebius Gallicanus », Collectio Homiliarum, XXXV (34), éd. F. GLORIÉ, Turnhout, 1970, p. 401-415. P. VIARD, s. v. «Fauste», in Dictionnaire d'histoire et de géographie ecclésiastiques, t. 16, Paris, 1967, col. 731-734. E. BOULARD, s. v. « Fauste de Riez », in G. GRENTE (éd.), Dictionnaire des lettres françaises, Paris, $1992^{2}$, p. 433. Les homélies 72 sur Honorat et 35 sur Maxime sont attribuées avec certitude à Fauste. Sur la datation du sermon de Fauste en faveur de Maxime: S. PRICoco, 
"Modelli di santità a Lerino. L'ideale ascetico nel Sermo de Vita Honorati di Ilario di Arles ", Siculorum Gymnasium, 27 (1974), p. 54-88 et ici p. 80, n. 63.

17. L. MELLET, «Quelques caractéristiques monastiques de la prédication pascale du PseudoEusèbe Gallican (i.e. Fauste de Riez)", in Il monachesimo occidentale dalle origini alla Regula Magistri, Rome, 1998, p. 179-195 et 181 (n. 12). P. BOULHOL et P.-A. JACOB, Maxime de Riez..., op. cit., p. 74-84.

18. Sidoine APollinaire, Poèmes, éd. A. Loyen, Paris, 1960, Carm. XVI, Euchariston ad Faustum episcopum, v. 109-115 et 127-128. EUCHER, De laude eremi, 42, éd. S. PRICOCO, Catania, 1964. D. AMHERDT, « Le Carmen 16 de Sidoine Apollinaire. L'Esprit Saint et les Muses, la Bible et Juvénal, Lérins et les Syrtes brûlantes ", in R. POIGNAULT et A. STOEHR-MONJOU (éd.), Présence de Sidoine Apollinaire, Clermont-Ferrand, 2014, p. 421-432.

19. BHL 5855 : GRÉGOIRE DE TOURS, Libri miraculorum, VIII, In Gloria confessorum, 82, in MGH, Scriptorum rerum merovingicarum, t. 1-2, Miracula et opera minora, éd. B. KRUSCH, Hanovre, 1885, p. 350-351. M. CARRIAS, «La connaissance des saints provençaux dans l'œuvre de Grégoire de Tours », Provence historique, 20 (1970), p. 317-339. P.-A. FÉVRIER, «Les saints évêques de la fin de l'Antiquité et du Haut Moyen Âge dans le sud-est de la Gaule (genèse et développement de leur culte)», Mémoires de l'Académie de Vaucluse, $7^{\mathrm{e}}$ sér., 6 (1985) [Le peuple des saints. Croyances et dévotions en Provence et Comtat Venaissin à la fin du Moyen Âge], p. 17-40.

20. P.-A. FÉVRIER, « Les saints évêques... », ibid., p. 22.

21. P. RICHÉ, Éducation et culture dans l'Occident barbare, VI ${ }^{e}-\mathrm{VIII}^{e}$ siècle, Paris, $1995^{4}$, p. 155. ID., « Note d'hagiographie mérovingienne : la Vita s. Rusticulce ", Analecta Bollandiana, 72 (1954), p. 376.

22. L'identification de l'auteur de la Vita Maximi avec Dynamius, patrice à Marseille pour le roi d'Austrasie, partisan des réseaux burgondes, recteur en Provence du patrimonium Petri pour le pape Grégoire, est probable. Sur les Dynamius : VenAnce fortunat, Poèmes, 2, liv. VI, 9 (composé vers 566) et 10, éd. M. REYDELLET, Paris, 1998, p. 80-84 et 180-181. Correspondance avec Grégoire le Grand, en 593 (MGH, Epistolo, t. 1, éd. P. EWALD et L. M. HARTMANN, Berlin, 1891, III-33, p. 191-192), évoqué en 595 (ibidem, VI-6, p. 384-385). K. F. STROHEKER, Der Senatorische Adel im Spätantiken Gallien, Tübingen, 1948, nº 108, p. 164-165. J.-P. POLY, « Agricola et ejusmodi similes : la noblesse romane et la fin des temps mérovingiens ", in M. sот (éd.), Haut Moyen Âge : culture, éducation et société. Études offertes à Pierre Riché, Paris, 1990, p. 204-206, qui propose une assimilation discutable avec un évêque d'Avignon. D. NORBERG, « Dyname Patrice de Marseilles », Journal of Medieval Latin, 1 (1991), p. 46-51. J. R. MARTINDALE, The Prosopography of the Later Roman Empire, a. d.527-641, Cambridge, 1992, p. 429-430. W. BERSCHIN et D. BLUME, «Dinamius Patricius von Marseille und Venantius Fortunatus ", in B. KÖRKEL, T. LICHT et J. WIENDLOCHA (éd.), Mentis amore ligati. Lateinische Freundschaftsdichtung und Dichterfreundschaft in Mittelalter und Neuzeit. Festgabe für Reinhard Düchting zum 65. Geburtstag, Heidelberg, 2001, p. 19-40. B. DUMÉZIL, «Gogo et ses amis : écriture, échanges et ambitions dans un réseau aristocratique de la fin du $\mathrm{VI}^{\mathrm{e}}$ siècle », Revue historique, 643 (2007), p. 553-593. ID., «Le patrice Dynamius et son réseau: culture aristocratique et transformation des pouvoirs autour de Lérins dans la seconde moitié du vi siècle ", in Y. coDou et M. LAuWers (éd.), Lérins, une île sainte..., op. cit., p. 167-194. M. HeIjMANS, s. v. «Dynamius 3 ", in Prosopographie chrétienne du Bas-Empire..., op. cit., t.4/1, p.600-603. P. BOULHOL et P.-A. JACoB, Maxime de Riez..., op. cit., p. 43-58. En revanche, Dynamius n'est assurément pas l'auteur de la Vita Marii (BHL 5540-5541; Patrologie latine, t. 80, Paris, 1863, col. 25-32) : T. PÉcout, Martyrologes de Provence, à paraître.

23. Urbicus est présent au concile de Valence, probablement tenu en juin 583 (Concilia Gallice a. 511-a. 695, éd. C. DE CLERCQ, Turnhout, 1963, p. 236 ; O. PONTAL, Histoire des conciles mérovingiens, Paris, 1989, p. 172 ; date rectifiée par J.-P. POLY, « La "Petite Valence"... », op. cit., p. 169, n. 9), ainsi qu'à celui de Mâcon en octobre 585 (Concilia Gallice a.511..., ibid., p. 249 ; O. PONTAL, Histoire des 
conciles..., ibid., p. 186-191) ; il est mentionné ensuite par Grégoire de Tours vers 589 (Histoire des Francs, 9, 41, éd. R. LATouche, Paris, 1996, p. 244), puis dans la lettre dédicatoire de la Vita Maximi de Dynamius (Patrologie latine, t. 80, Paris, 1863, col. 31-34 et GCNN, t. 1, Instr., $\mathrm{n}^{\circ}$ 10, col. 370-371, outre l'édition de Salvatore Gennaro). M. HEIJMANS, s.v. «Urbicus 3 ", in Prosopographie chrétienne..., op. cit., t. 4/2, p. 2007-2009.

24. Sur ce processus et ses caractéristiques: B. BEAUJARD, le culte des saints en Gaule. Les premiers temps, d'Hilaire de Poitiers à la fin du VI siècle, Paris, 2000. A. KRÜGER, Südfranzösische Lokalheilige zwischen Kirche, Dynastie und Stadt vom 5. bis zum 16. Jahrhundert, Stuttgart, 2002, pour les saints d'Arles, Aix, Marseille et Tarascon, dans leurs relations avec les pouvoirs et l'identité urbains.

25. Sur les liens entre implantations de confins diocésains et vocables de saints évêques: Y. CoDou, «Aux confins du diocèse : limites, enclaves et saints diocésains en Provence au Moyen Âge », in F. MAZEL (éd.), L'espace du diocèse dans l'Occident médiéval, Rennes, 2008, p. 195-212.

26. AA SS nov., t. II, 1, éd. J.-B. DE ROSSI et L. DUCHESNE, Bruxelles, 1894. AA SS nov., t. II, 2, éd. H. QUENTIN et H. DELEHAYE, Bruxelles, 1931.

27. M. CARRIAS, Saint Mitre d'Aix. Étude hagiographique, Aix-en-Provence, 1969, p. 241. P.-A. FÉVRIER, "Les saints évêques... », op. cit., p. 30, relève, outre les saints viennois, ceux d'Arles, de Toulon ou de Gap.

28. V. LEROQUAIS, Bréviaires manuscrits des bibliothèques publiques de France, Mâcon, 1934, p. 130-132. Voir aussi la bibliographie proposée dans V. SAXER, « Les calendriers liturgiques de Saint-Victor et le sanctoral médiéval de l'abbaye ", Provence historique, 16 (1966), p. 485, n. 56-58.

29. PARIS, BnF, lat. 5295, fol. 93-100, manuscrit provenant de la chapelle archiépiscopale d'Arles, $\mathrm{du} \mathrm{XI}^{\mathrm{e}}$ siècle, avec un ajout du siècle suivant pour la Vita Virgilii. BHL 8679 (MGH, Scriptores rerum Merovingicarum, t. 4, éd. B. KRUSCH, p. 337-451). L.-H. LABANDE, «Étude historique et archéologique sur Saint-Trophime d'Arles, du IV ${ }^{\mathrm{e}}$ au XIII ${ }^{\mathrm{e}}$ siècle », Bulletin monumental, 77 (1903), p. 459-497, ici p. 483-485. S. GENNARO, « La Vita S. Maximi ep. Reiensis e la Vita S. Virgilii ep. Arelatensis ", in Annuario 1964-1965 del Liceo-Ginnasio Mario Cutelli, 1966, p. 61-66. S. GIOANNI, «La "Vita Virgilii” (BHL 8679) : plagiat, réécriture ou remploi?", in M. GOULLET, M. HEINZELMANN et C. VEYRARD-COSME (éd.), L'hagiographie mérovingienne à travers ses réécritures, Paris, 2010, p.125-159. E. MAGNANI, "Trophimus, Dionisus, Regulus, Felicissimus... Listes et vies des premiers évêques d'Arles (IX $\mathrm{XII}^{\mathrm{e}}$ siècle) ", Provence historique, 66 (2016), p. 103-118. T. PÉCOUT, Le livre du chapitre du chapitre cathédral Notre-Dame de la Seds de Toulon, Paris, 2020, p. 59 (n. 1), 370 (n. 3) et 382 (n. 2).

30. M. CARRIAS, Saint Mitre d'Aix. Étude hagiographique, Aix-en-Provence, 1969, p. 244 et n. 1.

31. E. A. OVERGAAUW, Martyrologes manuscrits des anciens diocèses d'Utrecht et de Liège. Étude sur le développement et la diffusion du martyrologe d'Usuard, t. 1, Hilversum, 1993, passim.

32. PARIS, BnF, lat. 12410. On notera que le manuscrit de Corbie est apparenté à celui de l'abbaye de Saint-Wandrille rédigé à la fin du viII ${ }^{\mathrm{e}}$ siècle (J. DUBoIs, Les martyrologes du Moyen Âge latin, Turnhout, 1978, p. 31). Cette abbaye normande est l'un des centres du culte de Mauxe. Vies des saints et des bienheureux, t. 11, Paris, 1954, p. 938-939.

33. S. Gennaro ("Note sulla tradizione manoscritta della Vita sancti Maximi episcopi Reiensis », in Oikoumene. Studi paleocristiani in onore del concilio Ecumenico Vaticano II, Catane, 1964, p. 536, n. 6) s'accorde avec les conclusions d'É.Griffe («Les sermons de Fauste de Riez. La "Collectio gallicana" du Pseudo-Eusèbe », Bulletin de littérature ecclésiastique, 61 (1960), p. 27-38 et « Nouveau plaidoyer pour Fauste de Riez ", Bulletin de littérature ecclésiastique, 74 (1973), p. 187-192), qui luimême s'appuie sur la thèse inédite de J. Leroy à propos de la collection d'Eusèbe d'Émèse. Pour un aperçu des controverses concernant l'attribution de la collection dite d'Eusèbe le Gallican: J.P. WEISS, «Le statut de prédicateur et les instruments de la prédication dans la Provence du $V^{\mathrm{e}}$ siècle ", in R. M. DESSì et M. LAUWERS (dir.), La parole du prédicateur, $V^{e}$-XV $V^{e}$ siècles, Nice, 1997, p. 23-47 ; L. MELLET, «Quelques caractéristiques monastiques de la prédication pascale du PseudoEusèbe Gallican (i.e.Fauste de Riez)", in Il monachesimo occidentale dalle origini..., op. cit., 
p. 179-195. On notera la présence au XII ${ }^{\mathrm{e}}$ siècle d'autres textes issus de la collection d'Eusebius au monastère Saint-Laurent d'Avignon: V. SAXER et M. HAYEZ, "Documents inédits du ms. Casanatense 668 sur l'abbaye Saint-Laurent d'Avignon ", Mémoires de l'Académie de Vaucluse, $6^{\mathrm{e}}$ sér., 8 (1975), p. 91-116.

34. P.-A. FÉVRIER, « Les saints évêques... », op. cit., p. 20.

35. Sur Dynamius et Urbicus, voir n. 23.

36. Jusqu'au trait gras du tableau: S. GENNARO, "Note sulla tradizione manoscritta... ", op. cit., p. 535-545. À compléter par le compte rendu de Guy Philippart dans Analecta Bollandiana, 90 (1972), p. 203-207 et nos propres recherches dans les livres liturgiques.

37. Micy, com. de Saint-Pryvé-Saint-Mesmin, dép. du Loiret. Cette Vita (BHL 5814-5816) est éditée par Luc d'Achéry et Jean Mabillon (AASS OSB, Saec. I, Paris, 1668, p. 581-591), puis en partie dans les AASS (\$ 4-24) et en partie dans Catalogus codicum hagiographicorum latinorum antiquiorum saeculo XVI qui asservantur in Bibliotheca nationali Parisiensi, t. 1, Paris/Bruxelles, 1889, p. 300-303 (§ 25-35). Ce manuscrit a été utilisé et décrit par J.-C. Moulinier (Saint Victor de Marseille. Les récits de sa passion, Rome, 1993, p. 93-94) pour les passages concernant saint Victor. A. PONCELET, « Les saints de Micy ", Analecta Bollandiana, 24 (1905), p. 5-104. G. PHILIPPART, Les légendiers latins et autres manuscrits hagiographiques, Turnhout, 1977, p. 34-35, 38-39, 40-42, 52, 53, 83 et 102 (n. 86). F. DOLBEAU « Anciens possesseurs des manuscrits hagiograhiques latins conservés à la bibliothèque nationale de Paris », Revue d'histoire des textes, 9 (1979), p. 193. C. vullieZ, "Les Miracula sancti Maximini de Létald de Micy: prolégomènes à une nouvelle édition », in M. COUMERT et al. (éd.), Rerum gestarum scriptor. Histoire et historiographie au Moyen Âge. Hommage à Michel Sot, Paris, 2012, p. 623-636. ID., «Des concurrents sérieux aux hagiographes fleurisiens: culte des saints et productions hagiographiques à l'abbaye de Saint-Mesmin-de-Micy (fin $\mathrm{x}^{\mathrm{e}}$-début $\mathrm{XI}^{\mathrm{e}}$ siècle) ", in A. DUFOUR-MALBEZIN (éd.), Abbon, un abbé de l'an Mil, Turnhout, 2008, p. 369-388.

38. CITTÀ DEL VATICANO, Biblioteca Apostolica Vaticana, Reg. lat. 318 , fol. Iv $^{\circ}$ (Incipiunt capitula libri hujus. Vita sancti Maximi episcopi Regensis).

39. Les recensions de la Vita Maximi BHL 5853 figurant dans le dossier constitué par les Bollandistes [BRUXELLES, Bibliothèque royale de Belgique, ms. 8957-8958 (3512)] renvoient pour partie à ces manuscrits perdus : fol. 60-62 (ici Vita de Maxime de Vienne, manuscrit similaire à celui de Saint-Martin de Tournai comparé avec le «ms 1466 » de la reine de Suède), fol. 63-65v ${ }^{\circ}$ (d'après plusieurs manuscrits de la cathédrale de Thérouanne), fol. $67-72 \mathrm{v}^{\circ}$ (manuscrit de Saint-Omer collationné avec le manuscrit « 1466 » de la reine de Suède), fol. $74-80 \mathrm{v}^{\circ}$ (manuscrit de Nantua), fol. 85 prologue de Dynamius (manuscrit de Signy), fol. 86-93v ${ }^{\circ}$ (manuscrit de Saint-Claude, collationné avec les manuscrits de Signy, de Saint-Timothée [la collégiale de Reims vraisemblablement], de Vauluisant et de La Charité), fol. $94-95 \mathrm{v}^{\circ}$ (manuscrit de Saint-Sauveur d'Utrecht), fol. 96 (bréviaire de Saint-Pierre de Vienne : probablement GRENOBLE, BM, R 8640, vers 1570). Le manuscrit de Vauluisant est issu du sixième tome d'un légendier perdu en plusieurs volumes copié par Pierre-François Chifflet puis consulté par Denis Paprebroch en 1662: F. BOUGARD et P. PETITMENGIN, La bibliothèque de l'abbaye cistercienne de Vauluisant. Histoire et inventaires, Paris, 2012, p. 223-230.

40. F. DOLBEAU, « Notes sur la genèse et sur la diffusion du Liber de Natalitiis », Revue d'histoire des textes, 6 (1976), p. 149-150, 168-169 et 179-183 (annexes).

41. F. DOLBEAU, "Anciens possesseurs des manuscrits... », art. cit. n. 39, p. 147. Il est sans doute proche aussi du manuscrit de Dijon décrit ci-dessous n. 47.

42. M. COENS, «Analyse du légendier perdu de l'abbaye d'Acey près de Besançon, d'après les archives bollandiennes ", Analecta Bollandiana, 79 (1961), p. 360-388 ( $\left.{ }^{\circ} 204\right)$.

43. H. RochaIs, Liber de Natalitiis et autres légendiers du Moyen Âge, mémoire de doctorat de $3^{\mathrm{e}}$ cycle, Rochefort (Belgique), 1975, passim et t. 2, p. 57 et 122.

44. F. DOLBEAU, « Notes sur la genèse... », op. cit., p. 169, n. 2. 
45. Braine, dép. de l'Aisne, canton de Fère-en-Tardenois. La Vita est signalée au début du $\mathrm{XVII}^{\mathrm{e}}$ siècle par Nicolas de Beaufort $(\dagger 1624)$, mais la partie du recueil où elle figurait fait aujourd'hui défaut: A. BONDÉELLE, «D'un fonds monastique aux grandes collections actuelles. L'itinéraire d'un légendier de Braine ", Analecta Bollandiana, 117 (1999), p. 151-162. Il faut peutêtre rapprocher ce manuscrit de celui de CITTÀ DEL VATICANO, Biblioteca Apostolica Vaticana, Reg. lat. 1864, composé à Saint-Médard de Soissons (P. LAUER, Collections manuscrites sur l'histoire des provinces de France. Inventaire, t. 2, Paris, 1911, p. 106-107. Pierre-Nicolas Grenier (1725-1789), qui séjourne à Saint-Médard de Soissons en 1748-1753, a pu collecter ce manuscrit dans cette cité où la dévotion à Maxime de Riez est ancienne : un manuscrit de sa Vita, non interpolée il est vrai, en est originaire (CITTÀ DEL VATICANo, Biblioteca Apostolina Vaticana, Reg. lat. 1864, fol. 19-26, des XI $\mathrm{e}^{\mathrm{e}}$ $\mathrm{XII}^{\mathrm{e}}$ siècles). À la fin $\mathrm{du} \mathrm{XIX}^{\mathrm{e}}$ siècle, l'érudit provençal Jean-François Cruvellier repère ce remaniement de la Vita Maximi dans le fonds de dom Grenier (lettre au chanoine JosephHyacinthe Albanès du 21 novembre 1881: AD13, 26 F 26). Abrégé de la Vita Maximi interpolée: J. THÉROUDE, Abrégé de la vie de s. Maxime ou Maxe, évesque de Riez en Provence, apostre du Teroüennois, et patron de la ville de Vernon sur Seine, au diocèse d'Évreux. Ensemble quelques miracles faits au dit lieu de Vernon par l'intercession de ce saint, Paris, 1635).

46. Il se pourrait même que Barralis n'ait fait que suivre l'édition de Sauer. L. SURIUS, De probatis sanctorum historiis, t. 6, Cologne, 1575, p. 601-606 et Patrologie latine, t. 80, Paris, 1863, col. 31-40, qui reprend Barralis. V. BARRALIS, Chronologia sanctorum et aliorum virorum illustrium ac abbatum sacrce insule Lerinensis, t. 2, Lyon, 1613, p. 120-126. Dinamii vita sancti Maximi..., op. cit., p. 34-35.

47. DIJON, BM, ms. 642, fol. 33-35 : XIIII. Incipit vita sancti Maximi episcopi et confessoris. Beatissimi Maximi Regensis urbis antistitis hodierna die [...] unacum spiritu sancto in secula seculorum amen. A. MOLINIER et al., Catalogue général des manuscrits des bibliothèques publiques de France. Départements, t. 5 (Dijon), Paris, 1889, p. 166-181. C. OURSEL, La miniature du XII' siècle à l'abbaye de Cîteaux d'après les manuscrits de la Bibliothèque de Dijon, Dijon, 1926. M. CoENS, "Analyse du légendier perdu de l'abbaye d'Acey près de Besançon d'après les Archives bollandiennes ", Analecta Bollandiana, 79 (1961), p. 361-388, ici p. 362-364. A. PERONI, "San Salvatore di Brescia: un ciclo pittorico altomedievale rivisitato", Arte medievale, Periodico internazionale di critica dell'arte medievale, 1 (1983), p. 53-80, ici p.51-72. Y. ZALUSKA, L'enluminure et le scriptorium de Cîteaux au XII siècle, Cîteaux, 1989, p. 223-225, nº 17. Y. ZALUSKA et al., Manuscrits enluminés de Dijon, Paris, 1991, p. 80, $\mathrm{n}^{\circ} 37, \mathrm{pl}$. XXVI et XXVII. D. J. REILLY, The Cistercian reform and the art of the book in twelfth-century France, Amsterdam, 2018, p. 22, 80, 81, 99 et 121.

48. Un sommaire au folio 4 , qui serait un autographe d'Hugues de Lincoln, dénombre ainsi le contenu du livre: les vies d'Honorat par Hilaire de Poitiers (BHL 3975) fol. 7-19v' d'Hilaire par Venance Fortunat (BHL 3885) fol. 19vº-24, d'Hugues de Grenoble par Guigues (BHL 4016) fol. 24-35, de Cyprien de Carthage par l'archidiacre Pons (BHL 2041) fol. 35-42, de Maxime par Dynamius (BHL 5853) fol. 42-49, de Martin de Tours par Sulpice Sévère $(B H L 5610,5613)$ et Grégoire de Tours

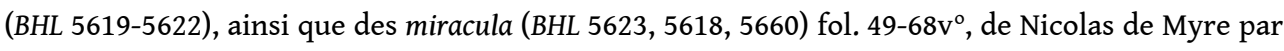
Jean Diacre (BHL 6104-6106 et en partie 6110) fol. $68 \mathrm{v}^{\circ}-81$, avec un extrait des Institutes de Cassiodore fol. 81-83, et la vie de Malachie par Bernard de Clairvaux (BHL 5188) fol. 83-112 $\mathrm{v}^{\circ}$, outre du même un sermon sur la translation du même saint irlandais et une lettre fol. $112 \mathrm{v}^{0}-116 \mathrm{~V}^{0}$. Pour les trois vies les plus récentes : P. CORSI, « La "Vita" di san Nicola e un codice della versione di Giovanni diacono", Nicolaus. Rivista di teologia ecumenico-patristica, 7 (1979), p. 361-380 ; GUIGUES I, Vita S. Hugonis episcopi Gratianopolitani, éd. C. BELLET, Montreuil-sur-Mer, 1889 ; BERNARD DE CLAIRVAUX, The Life and Death of St. Malachy the Irishman, trad. R. T. MEYER, Kalamazoo, 1978, p. 11-93 (Vita) et p. 107-112 (sermon) ; BERNARD DE CLAIRVAUX, Éloge de la nouvelle chevalerie. Vie de saint Malachie. Épitaphe, Hymne, Lettres, trad. P. Y EMERY, Paris, 1990.

49. LINCOLN, Cathedral, 107 (A.4.15), Libellum de vita patrum in rubeo coopertario, fol. 42-49. H. FARMER, in Bibliotheca sanctorum, t.12, Rome, 1969, col.765-767; ID., Saint Hugh of Lincoln, Londres/ 
Kalamazoo, 1985. Originaire d'Avalon (com. de Saint-Maximin) près de Grenoble, ancien chanoine régulier à Villardbenoît (com. de Pontcharra), chargé de la celle de Saint-Maxime, puis moine à la Grande Chartreuse, il est appelé en 1179 en Angleterre pour encadrer comme prieur la récente fondation royale de Witham, dans le diocèse de Bath. À l'occasion d'un voyage diplomatique commandité par Henri II auprès de Philippe Auguste, il se rend à nouveau à Avalon et Villardbenoît vers 1199-1200, puis visite Saint-Omer, Clairmarais et Reims. Il meurt le 17 février 1200. Sa Vita est rédigée par son chapelain Adam d'Eynsham; il est canonisé en 1221 (BHL 4018 ; Magna Vita Sancti Hugonis: The Life of Saint Hugh of Lincoln, éd. D. L. DOUIE et H. FARMER Oxford, $1985^{2}$ ). H. E. J. COWDREY, « Hugh of Avalon Carthusian and Bishop », in M. G. SARGENT (dir.), De cella in seculum. Religious and Secular Life and Devotion in Late Medieval England, Cambridge, 1989, p. 41-58. GERALD OF WALES, The life of Saint Hugh of Avalon, Bishop of Lincoln, 1186-1200, éd. R. M. LOOMIS, Merchantville (NJ), 2014.

50. Magna Vita Sancti Hugonis : The Life of Saint Hugh of Lincoln, éd. D. L. DOUIE et H. FARMER, Londres/ Toronto/New York, 1961, t. 1, p. 18-19 et t. 2, p. 171-172.

51. W. KAY, Living Stones the Practice of Remembrance at Lincoln Cathedral (1092-1235), Ph. D., University of Saint-Andrews, 2013 (dactylographié), p. 132-133.

52. J. VAN DEN GHEYN, Catalogue des manuscrits de la bibliothèque royale de Belgique, t. 5 (Histoire, hagiographie), Bruxelles, 1905, $\mathrm{n}^{\circ}$ 3512, Collectanea Bollandiana, p. 581-583.

53. Sur les précisions chronologiques des témoignages collectés par Grégoire : M. CARRIAS, Saint Mitre d'Aix. Étude hagiographique, Aix-en-Provence, 1969, p. 104-111.

54. Signalée par L.-H. LABANDE, «Étude historique et archéologique sur Saint-Trophime d'Arles du $\mathrm{IV}^{\mathrm{e}}$ au XIII ${ }^{\mathrm{e}}$ siècle ", Bulletin monumental, t77 (1903), p. 459-497, ici p. 483-485.

55. Catalogus codicum hagiographicorum latinorum antiquiorum saeculo XVI qui asservantur in Bibliotheca nationali Parisiensi, t. 1, Paris/Bruxelles, 1889, p. 567-568.

56. A. PONCELET, «Le légendier de Pierre Calo», Analecta Bollandiana, 29 (1910), p. 5-116, ici p. 30-35, 95 et 106. C. Gennaro, s. v. "Calò Pietro », in Dizionario degli Italiani, t. 16, Rome, 1973, p. 787-789.

57. Michel Le Quien (1661-1733) OFP, originaire de Boulogne-sur-Mer, a rédigé un Abrégé de l'histoire de Boulogne-sur-Mer et ses comtes (P. N. DESMOLETS, Continuation des Mémoires de littérature et d'histoire, t. 10, $1^{\text {re }}$ partie, Paris, 1749, p. 36-112). S. SALAVILLE, « $\mathrm{II}^{\mathrm{e}}$ centenaire de Michel Le Quien († 1733-1933) », Échos d'Orient, t. 32, fasc. 171 (1933), p. 257-266.

58. V. TABBAGH, Fasti Ecclesice Gallicance, t. 20 (Diocèse d'Évreux), Turnhout, 2020, p. 122-125.

59. Classement par province et par ordre chronologique. I = V. LEROQUAIS, Les Sacramentaires et les missels manuscrits des bibliothèques publiques de France, Mâcon, 1924. II = V. LEROQUAIS, Les Psautiers manuscrits des bibliothèques publiques de France, Mâcon, 1940-1941. III = V. LEROQUAIS, Les Bréviaires manuscrits des bibliothèques publiques de France, Mâcon, 1934.

60. L. DONI D'ATTICHY, Officia propria sanctorum sanctee Regiensis Ecclesice, Aix, 1635, p. 2. N. DE VALAVOIRE, Officia propria sanctorum Ecclesice Regiensis, Aix, 1675. G. DE MANTEYER, «Les origines chrétiennes de la Deuxième Narbonnaise, des Alpes-Maritimes et de la Viennoise (364-483)", Bulletin de la Société d'études historiques, scientifiques et littéraires des Hautes-Alpes, $5^{\mathrm{e}}$ sér., 43 (1924), p. 36-37 et n. 114.

61. L. DONI D'ATTICHY, Officia propria sanctorum sanctce..., ibid., p. 10. 


\section{RÉSUMÉS}

Maxime, abbé de Lérins puis évêque de Riez (Alpes-de-Haute-Provence), voit son culte se déployer dès les lendemains de sa mort à la fin du ve siècle. Il illustre la plasticité des dévotions à l'égard de moines évêques reposant sur un antique corpus hagiographique. Elles sont certes attachées à une identité diocésaine locale, mais rejoignent précocement un groupe classique de vénérables modèles circulant à large échelle via les collections de légendiers et les éloges martyrologiques. Maxime fut l'objet d'appropriations diverses, en Flandre, en Viennois, en Italie du nord, notamment, dont les ressorts sont examinés. Le dossier hagiographique de Maxime nécessitait une reconstitution et une relecture à diverses échelles.

Maxime was bishop of Riez (Alpes-de-Haute-Provence) after having been abbot of Lérins. His worship spread immediately after his death at the end of the 5th century. The exemple of Maxime illustrates the plasticity of the cult of a monk and bishop based on an ancient collection of hagiographical works. Worship is attached to a local diocesan identity but soon merges with a classic set of prestigious models that widely circulate through collections of saints'lives and martyrologies. Maxime has been the object of various appropriations, especially in Flanders, in the Viennois, and in northern Italy, the sources of which are examined here. The hagiographic file of Maxime needs a reconstitution and a rereading on various levels.

\section{INDEX}

Mots-clés : hagiographie, Maxime de Riez, saint évêque, cathédrale, reliques, Provence, Riez, Thérouanne, Vie de saint, miracle

Keywords : hagiography, Maxime of Riez, saint bishop, cathedral, relics, Provence, Riez, Thérouanne/Terwaan, Life of saint, miracle

\section{AUTEUR}

\section{THIERRY PÉCOUT}

Professeur des Universités, histoire du Moyen Âge, université Jean Monnet (Saint-Étienne, France), UMR 8584 Laboratoire d'études des monothéismes - CERCOR [Centre européen de recherche sur les communautés, congrégations et ordres religieux] 